\title{
Complexity Analysis of Pricing in a Multichannel Supply Chain with Spillovers from Online to Offline Sales
}

\author{
Fengxia Mai, ${ }^{1,2}$ Jianxiong Zhang $\left(\mathbb{D},{ }^{1}\right.$ Rui Yang, ${ }^{1}$ and Xiaojie Sun $\mathbb{D}^{1,3}$ \\ ${ }^{1}$ College of Management and Economics, Tianjin University, Tianjin 300072, China \\ ${ }^{2}$ School of Science, Tianjin University of Commerce, Tianjin 300134, China \\ ${ }^{3}$ Rowe School of Business, Dalhousie University, Halifax, NS B3H 4R2, Canada \\ Correspondence should be addressed to Xiaojie Sun; xj933918@dal.ca
}

Received 20 March 2020; Revised 31 May 2020; Accepted 18 June 2020; Published 14 July 2020

Academic Editor: Abdelalim A. Elsadany

Copyright ( 92020 Fengxia Mai et al. This is an open access article distributed under the Creative Commons Attribution License, which permits unrestricted use, distribution, and reproduction in any medium, provided the original work is properly cited.

In recent years, many manufacturers have been selling their products to online consumers through e-tailers by adopting reselling mode and agency selling mode simultaneously. The sales from the online channels inevitably incur spillover effect to the traditional offline channels. This paper develops a dynamic pricing game model on the basis of a long-term gradient adjustment mechanism for a multichannel supply chain that consists of a manufacturer and an e-tailer and focuses on examining the impacts of spillover effect, agency fee, and adjustment speed on the stability and complexity of the dynamic game system. The results show that both a greater spillover effect and a higher agency fee can make the dynamic game system more stable, and a higher adjustment speed can destabilize the dynamic game system through period doubling bifurcation. Furthermore, it is interesting to find that the destabilization of the game system benefits the e-tailer and the supply chain while having little influence on the manufacturer, and thus the dynamic adjustment strategy may improve the supply chain efficiency.

\section{Introduction}

E-commerce has witnessed rapid growth in the past decade and has been occupying market share previously dominated by physical stores, making up $10.2 \%$ of the global retail sales in 2017 [1]. According to reports, the sales of online retailing reached $\$ 2.304$ trillion in 2017 , with a $24.8 \%$ increase over the previous year [1]. With the increasing prevalence of online retailing and the implementation of platform opening plan (POP), e-tailers have begun to allow manufacturers to directly access online consumers with charging a commission fee for providing this platform. This agency selling mode has been embraced by some prominent online retailers, such as Taobao and JD [2] in China, Amazon in the US, and Flipkart in India [3]. In addition to agency selling, manufacturers also have an alternative selling mode in practice, i.e., the reselling mode, where e-tailers who act as conventional merchants wholesale from manufacturers and resell to consumers. As one of the largest online retailers in China, JD adopted the two online selling modes simultaneously and significantly benefited from this retail structure, according to the financial report in 2018 (https:// www.chyxx.com/industry/201807/661976.html).

The boom of online retailing has raised the concern about whether brick-and-mortar stores will give way to e-commerce. "Online-only will not survive, all businesses need to integrate online and offline resources," Jianlin Wang, the chairman of Dalian Wanda Group said [4]. Nowadays, more and more manufacturers are able to sell their products in a multichannel supply chain, i.e., they sell not only through physical stores but also through e-tailers' channels in the reselling mode and the agency selling mode; for instance, manufacturers, including Huawei, Gree, Haier, Midea, and Xiaomi, sell their products via multichannel selling to improve their performance. Particularly, Xiaomi, who is a major Chinese smart phone vendor, sells through a large online retail platform JD and also sells through physical stores to offline consumers directly, in a bid to make its products more accessible [5]. Such an offline expansion strategy appears to be paying off, since Xiaomi bounces back 
with a $70 \%$ increase in shipments as compared with the previous quarter [6]. Therefore, how the coopetition between supply chain members and the interactions between online selling and offline selling affect the pricing strategy of firms has become a critical problem to be addressed in multichannel supply chain management.

Spillover effect usually arises in a multichannel supply chain and gives rise to complex effects in which the sales of offline selling are influenced by that of online selling. There are several studies taking spillover effect into consideration and exploring the interactions between online selling and offline selling. Abhishek et al. [7] investigated the interactions between online selling and traditional selling and suggested two competitive and homogeneous e-tailers' preferences for reselling mode and agency selling mode in the presence of spillover effect. They also found that if there is negative spillover effect, e-tailers prefer the agency selling channel; otherwise, they prefer the reselling channel. By measuring the combined impacts of the online spillover effect, the platform fee, and the manufacturer's inefficiency in selling, Yan et al. [8] focused on whether and under what conditions the marketplace channel should be introduced. However, all the above researches are based on the assumption that the decision makers know full information about the market and can make pricing decisions accurately. That is, the decision makers are fully rational and make pricing decisions on the basis of a static one-shot pricing game model. In practice, due to limited opportunities to learn the market information, the decision makers are usually boundedly rational and have to make decisions based on the limited information, which will lead to a dynamic repeated game process for the players. That is, the decision makers can adjust pricing decisions through a long-term gradient adjustment mechanism to achieve their maximum profits. In consideration of the players' bounded rationality, it is still unclear how spillover effect influences the interactions between online selling and offline selling, which deserves further investigation.

When players with bounded rationality implement dynamic pricing strategy, it is important to identify how spillover effect affects the dynamic evolution, system stability, and players' profits when e-tailers have more exact information. In the context of dynamic game, there are an increasing number of studies investigating a multichannel supply chain or marketing competition. For instance, considering the service value in a dual-channel supply chain, Zhang and Wang [9] developed two dynamic pricing strategies and examined the effect of service value on players' decisions. Ma and Xie [10] developed the dynamic game models in a dual-channel supply chain consisting of a manufacturer and a retailer, considering two scenarios in which the manufacturer holds either asymmetric or symmetric channel power to the retailer, and compared the complex behavior under different channel power structures via numerical simulation. Guo [11] explored channel conflict taking into consideration the impacts of online consumer reviews in a dual-channel supply chain from a dynamic perspective and analyzed the stability of the equilibrium point and complexity of channel conflict.
Taking the input of a retailing service into account, Ma et al. [12] investigated a dual-channel dynamic game and explored the stability of the equilibrium point and further made a discussion about the effects of the adjustment speed on the complexity of the game system and the market performance. In addition, for dynamic analysis, Naimzada and Pireddu [13] explored the dynamic behavior of the fashion cycle by investigating the asymptotic heterogeneity among agents and found that the global dynamics may differ according to the chosen functional form for the attractiveness. Naimzada and Pireddu [14] also examined the globally eductive stability of a Muthian cobweb model in a profit-based evolutionary setting, assuming that agents face heterogeneous information costs. Baiardi and Naimzada [15] investigated the stability properties of a dynamic model of a linear Cournot oligopoly considering rational agents and indicated that the heterogeneities among players influence the stability of the Cournot-Nash equilibrium. Baiardi et al. [16] also studied the stability properties of a Minskyan type model formulated in a discrete time framework and showed that its stability and complexity depend on either a subcritical flip or a supercritical Neimark-Sacker bifurcation. Different from the above existing literatures, our paper focuses on the dynamic repeated pricing game in a multichannel supply chain, especially on the impact of spillover effect from online to offline on the complexity and dynamics of the game system.

In addition, it is necessary to explore the different profit distributions among participants if e-tailers allow manufacturers to directly have an access to their online consumers, which is related to the topic of supply chain coordination, and this topic has attracted significant academic interest (e.g., [17-23]). Players can coordinate the supply chain through a variety of mechanisms, such as twopart tariff contract, rebate contract, quantity discounts contract, and revenue-sharing contract, among which revenue-sharing contract has been universally applied in industries and widely explored by researchers. For instance, Zhang et al. [23] considered a two-echelon deteriorating item supply chain with a manufacturer and a retailer over an infinite time horizon, where a revenue-sharing and cooperative investment contract is designed to coordinate the supply chain. Yan [22] found that although differentiated branding effectively alleviates channel competition and conflict, it is not sufficient to achieve full channel coordination, and a profit sharing mechanism is necessary. Note that agency selling works as a revenue-sharing mechanism to some extent. However, in a long-term dynamic pricing process, the effects of agency selling on the evolution features of the game system and the supply chain members' profits are still indistinct, which is worth to be further studied.

In this paper, we develop a dynamic pricing model for a multichannel supply chain where a manufacturer sells through not only the traditional offline stores but also e-tailers' online channels in both the reselling mode and the agency selling mode under a static one-shot game and a dynamic repeated game, respectively. We focus on the dynamic game in which the manufacturer with bounded rationality employs a long-term gradient adjustment 
mechanism to adjust the pricing decisions for improving profitability. We aim to investigate the impacts of spillover effect from online sales to offline sales, adjustment speed, and agency fee on the stability and complexity of the dynamic game system. By resorting to a large number of numerical studies with depicting the stability region, bifurcation diagrams, basin of attraction, and critical curve, we obtain some meaningful results for the multichannel supply chain. The results show that both a greater spillover effect and a higher agency fee can make the dynamic game system more stable, and a higher adjustment speed can destabilize the dynamic game system through period doubling bifurcation. Furthermore, it is interesting to find that the destabilization of the game system benefits the e-tailer and the supply chain while having little influence on the manufacturer, and thus the dynamic adjustment strategy may improve the supply chain efficiency.

In summary, the main contributions of the paper are presented as follows. First, our work extends the existing literatures considering the impacts of spillover effect and dealing with reselling and agency selling in a platform-based retailing market with rational decisions to the case of decision-making under bounded rationality, where the supply chain members cannot obtain complete market information which prevents them from making perfect decisions. Specifically, we make a leading effort to present a dynamic game for the multichannel supply chain in which the manufacturer changes the prices dynamically with the impacts of spillover effect. Second, we analyze the complex changes in the prices and profits of the supply chain members in the long-term pricing decision strategy. In particular, we investigate the impacts of the agency fee and spillover effect on the static game and also on the stability and complexity in the long-term dynamic game and obtain some interesting managerial insights.

The remainder of the paper is organized as follows. Section 2 presents the problem description and model setup. Section 3 gives the static game model and the dynamic game model (the repeated game) and conducts complexity analysis for the dynamic game, focusing on the impacts of key system parameters on the players' profits and the stability of the game equilibria. Finally, Section 4 concludes the paper.

\section{Problem Description and Model Setup}

2.1. Online Channel Structure. We consider a supply chain consisting of a manufacturer (she, denoted by subscript $m$ ) and an e-tailer (he, denoted by subscript $r$ ). The manufacturer cooperates with the e-tailer to sell her product on the electronic channel (e-channel, $E$ ) to online consumers. They cooperate through the reselling mode in which the e-tailer buys the product from the manufacturer at a unit wholesale price $w$ and then sells to online consumers at price $p_{r}$. In addition, the agency selling mode is also applied, in which the e-tailer offers the manufacturer direct access to his consumers with charging an agency fee for providing this service. The manufacturer sells to online consumers directly via the e-tailer's platform at price $p_{m}$ with paying a fraction $\delta$ of the profit as the agency fee to the e-tailer. In this paper, we assume a constant linear agency fee contract used by the e-tailer, as it is widely adopted in the literature on platform (e.g., $[7,24]$ and is generally applied in practice such as Taobao, JD, and Amazon.

2.2. Online Demand Specification. Note that online consumers can choose from one of the available options: (i) buying through the reselling channel and (ii) buying through the agency selling channel. For example, when consumers choose products from the JD platform, they can find self-run products from JD and direct selling products from direct sale stores. Similar to Abhishek et al. [7] and Lu et al. [25], we assume that the products sold through the two e-channels are symmetric substitutes, i.e., the substitution degree of the agency selling product (the e-tailer's product) over the reselling product (the manufacturer's product) equals that of the latter over the former. Then, the consumer demand for the product can be captured by a linear and downwardsloping inverse demand function, $q_{k}=\alpha_{k}-p_{k}+\gamma p_{l}$, $k, l \in\{m, r\}$ and $k \neq l$, where $p_{k}$ and $q_{k}$ represent the market clearing price and the product quantity for the e-tailer or the manufacturer, respectively, and the parameter $\alpha_{k}$ denotes product $k$ 's market potential. The parameter $\gamma \in[0,1]$ measures the substitution degree between the two e-channels' products, and the products become more homogeneous and the retail market is more competitive as $\gamma$ increases. Note that the two retail products turn out to be perfect substitutes when $\gamma$ approaches 1 and independent when $\gamma$ approaches 0 . We normalize the slope of this inverse demand function to be -1 , which is widely used in the modelling literatures on online selling [7, 26-28].

2.3. Online Spillover Effect. To incorporate the spillover effect, similar to Abhishek et al. [7] and Yan et al. [8], we assume that there already exists a brick-and-mortar retail channel (i.e., traditional channel) where the manufacturer sells the product at a unit price normalized to 1 with a base demand $\widetilde{Q}$, which represents the general demand of the traditional channel when the manufacturer does not sell online. The sales of traditional channel are influenced by the sales through the e-channels. Note that it is assumed that the manufacturer sells her product through e-channels only by a single e-tailer with the total demand for the manufacturer in the e-channels given by $q_{E}=q_{e}+q_{m}$. We formulate the spillover effect by assuming that the sales in the traditional channel are $\widetilde{Q}+\tau q_{E}$, where the parameter $\tau$ represents the net overall cross-channel effect that the e-channels place on the sales of the traditional channel.

More specifically, the parameter $\tau$ captures the quantity change in traditional sales brought by per unit sold through the e-channels. In our work, we restrict $\tau \in[-1,1]$. This model formulates an increase with $\tau>0$, a decrease with $\tau<0$, or no effect when $\tau=0$ in traditional channel sales for per unit sold by the e-channels. Note that the online sales will have a negative cross-influence on sales in the traditional channel if $\tau<0$. This could be due to cannibalization, i.e., consumers who have bought from online are less likely to purchase the same products from the physical stores. This 
negative effect is widespread in reality, especially for durable goods that will not be purchased again in the near period. However, various studies also report that spillover effect can sometimes stimulate offline sales and has a positive cross effect, i.e., $\tau>0$, under which per unit sold through the e-channels can result in $\tau$ units increased sales in the traditional channel. One reason for this increase could be wordof-mouth effect; for example, if a consumer who has been recommended e-book through push service or bought an e-book on Apple's iBook store or Amazon Kindle discusses the book to her/his acquaintances, then they may buy the physical book from a bookstore. Moreover, consumers who have very high regard for certain pieces of music or books often buy print editions to collect, commemorate, and display. This is in line with previous studies that cross effect can be negative or positive in different cases [29].

In addition, we assume that the product price in the traditional channel takes a constant value, which can be driven by two reasons. First, there exists operational difficulty in adjusting the product price in the traditional channel. In practice, the prices of physical books have not been affected by the e-book pricing. Moreover, prices are marked on books or special goods and cannot be changed as frequently as the prices in the e-channels. Second, the baseline demand $\widetilde{Q}$ is sufficiently high as compared to the small-scale demand from the cross-channel effect, since online sales account for $11 \%$ of the total sales at most [30]. From this point of view, the product price in the traditional channel is not influenced. Besides, Abhishek et al. [7] further extended their model to consider endogenous consumer choice across the electronic and traditional channels and reported that the results remain unchanged qualitatively. Thus, we concern the qualitative nature of spillover effect in the multichannel supply chain and consider this model in absence of the endogenous consumer choice across the electronic and traditional channels. For brevity, we normalize the product price in the traditional channel to 1 .

\section{Game Models and Analysis}

In this section, we first consider the case where the participants of the game are fully rational, which will lead to a static one-shot game. For convenience, we name this case as the static game model. And then, we focus on the case in which the participants with bounded rationality are involved in a dynamic repeated game, which is referred to as the dynamic game model.

3.1. Static Game. Consider a product distribution system in which a manufacturer cooperates with an e-tailer to sell her product to online consumers through two e-channels: the reselling channel and the agency selling channel. The manufacturer also sells her product through a traditional brick-and-mortar channel, which is either positively or negatively affected by the online sales volume. The e-tailer chooses to sell the product as a reseller (we name this as the wholesale configuration) and also enters into an agency selling arrangement with the manufacturer where the e-tailer acts as an agency seller (we name this as the agency configuration). This model also characterizes the asymmetry in sales efficiency between the e-tailer and the manufacturer by normalizing the e-tailer's unit selling cost to zero but denoting $c(>0)$ as the manufacturer's unit direct selling cost. This assumption is widely applied in the literature $[8,31,32]$ and is also reasonable in practice because e-tailers often have an advantage in the sales process as compared to the manufacturer. The retailer's advantage may stem from superior knowledge of customer preferences and more direct contact with customers or from economies of scope with other retailing activities and logistics [31]. Particularly, in the e-commerce environment, economies of scale in logistics are increasingly significant. For example, JD's self-logistic network has operated for 9 years and covers $98 \%$ of consumers in China; this powerful logistics network and the continuous technological innovation will provide substantial economies of scale for JD. As common in the literature, we further normalize the production cost of the manufacturer to zero due to her production advantage. This assumption aims to simplify the mathematical derivations of the model while preserving the fundamental qualitative results in the problem.

Given the above considerations, the manufacturer's profit is related to the profit from the e-channels, sales in the traditional channel, and the spillover effect from the e-channels to the traditional channel and is given as

$$
\pi_{M}=1 \cdot\left(\widetilde{Q}+\tau Q_{E}\right)+w q_{r}+(1-\delta)\left(p_{m}-c\right) q_{m},
$$

where $\delta$ denotes the agency fee from the manufacturer to the agency e-tailer and is assumed to be an exogenous factor since the platform fee is generally a longer-term and largerscale decision as compared to the pricing strategy. Besides, the agency fee charged by the e-tailer is mainly related to the product category, which means that it will not be adjusted for one specific manufacturer or one specific type of product. For instance, JD charges 7\% for clothes and shoes and 10\% for audiovisual products; Amazon charges 12\% to 30\% for e-book [33]. Considering the revenue from the agent fee and combining the sales revenue from the reselling channel, the profit function of the e-tailer can be formulated as

$$
\pi_{E}=q_{r}\left(p_{r}-w\right)+\delta\left(p_{m}-c\right) q_{m} .
$$

Then, the profit of the supply chain is given by

$$
\pi_{T}=\pi_{E}+\pi_{M}=\left(p_{m}-c\right) q_{m}+p_{r} q_{r}+1 \cdot\left(\widetilde{Q}+\tau Q_{E}\right) .
$$

For most cases in the multichannel supply chain, the manufacturer usually holds more market power than the e-tailer, because the manufacturer produces and owns the products, and first decides the wholesale price in the reselling channel and the retail price in the agency selling channel. Thus, the manufacturer is the leader, and the e-tailer is the follower, which constitutes a typical Stackelberg game. The sequence of events is as follows: first, the manufacturer determines the wholesale price $w$ under a wholesale contract and the retail price $p_{m}$ under an agency contract simultaneously; then, given the manufacturer's wholesale price $w$ and retail price $p_{m}$, the e-tailer sets his 
retail price $p_{r}$ in the reselling channel; and finally, the profits of the manufacturer and the e-tailer are realized.

By backward induction, the e-tailer's response function to the manufacturer's announcement of $w$ and $p_{m}$ can be obtained by setting $\left(\partial \pi_{E} / \partial p_{r}\right)=0$ and is given as

$$
p_{r}=\frac{1}{2}\left(\alpha_{r}+w+\gamma p_{m}+\delta \gamma p_{m}-\delta \gamma c\right) .
$$

The manufacturer makes decisions based on the response function. We substitute (4) into the manufacturer's profit function in (1) and obtain

$$
\begin{aligned}
\pi_{M}\left(w, p_{m}\right)= & \widetilde{Q}+\tau\left(\frac{1}{2} \gamma\left(\delta(1-\gamma)\left(c-p_{m}\right)+p_{m}(1+\gamma)+w+\alpha_{r}\right)-p_{m}+\frac{1}{2}\left(\alpha_{r}-w\right)+\alpha_{m}\right) \\
& +\frac{1}{2}\left(\gamma p_{r}(1-\delta)+c \delta \gamma+\alpha_{r}-w\right) w+(1-\delta)\left(\frac{1}{2} \gamma\left(\gamma p_{m}(1+\delta)+w+\alpha_{r}-c \delta \gamma\right)\right) \\
& \left.-p_{m}+\alpha_{m}\right)\left(p_{m}-c\right) .
\end{aligned}
$$

Then, the manufacturer decides the optimal wholesale price $w$ and the retail price $p_{m}$. Before maximizing the profit, we should assure that the function in (5) is concave in $w$ and $p_{m}$. The Hessian matrix of (5) is

$$
H_{\pi_{M}}\left(w, p_{m}\right)=\left(\begin{array}{cc}
-1 & (1-\delta) \gamma \\
(1-\delta) \gamma & (1-\delta)\left(\gamma^{2}(1+\delta)-2\right)
\end{array}\right) .
$$

The first-order principal minor of matrix $H_{\pi_{M}}$ in (6) is -1 , and the second-order one is $2(1-\delta)\left(1-\gamma^{2}\right)$. Because $0<\delta<1$ and $0<\gamma<1$, it is clear that $2(1-\delta)\left(1-\gamma^{2}\right)>0$. Therefore, the matrix $H_{\pi_{M}}$ is negative definite, meaning that the profit function of the manufacturer is concave and has a unique maximum solution. The marginal profit can be calculated as

$$
\begin{aligned}
& \frac{\partial \pi_{M}}{\partial w}=(1-\delta) \gamma p_{m}-w+A_{1}, \\
& \frac{\partial \pi_{M}}{\partial p_{m}}=(1-\delta)\left(\gamma^{2}(1+\delta)-2\right) p_{m}+(1-\delta) \gamma w+A_{2},
\end{aligned}
$$

where $\quad A_{1}=(1 / 2)\left(\alpha_{r}+2 c \delta \gamma-\gamma c-\tau(1-\gamma)\right) \quad$ and $A_{2}=(\tau / 2)\left(\gamma^{2}(1+\delta)+\gamma \quad(1-\delta)-2\right)+(1-\delta)(\gamma / 2$ $\left.\left(\alpha_{r}-c \delta \gamma\right)+\alpha_{m}-\left(\gamma^{2} / 2(1+\delta)-1\right) c\right)$. Then, the manufacturer's equilibrium can be obtained via the first-order conditions and is given as

$$
\begin{aligned}
& w^{*}=\frac{A_{1}\left(2-\gamma^{2}(1+\delta)\right)+A_{2} \gamma}{2\left(1-\gamma^{2}\right)}, \\
& p_{m}^{*}=\frac{A_{2}+A_{1} \gamma(1-\delta)}{2(1-\delta)\left(1-\gamma^{2}\right)} .
\end{aligned}
$$

Substituting (8) and (9) into (4), the e-tailer's optimal retail price can be generated and is presented as

$$
p_{r}^{*}=\frac{\left(c \delta^{2} \gamma+\alpha_{r}\right)\left(1-\gamma^{2}\right)+\delta\left(c \gamma^{3}+\alpha_{r}\left(1-\gamma^{2}\right)-c \gamma-A_{1}\right)+A_{1}+A_{2} \gamma}{2(1-\delta)\left(1-\gamma^{2}\right)} .
$$

Then, we can obtain the profits of the manufacturer, the e-tailer, and the supply chain in this unique static equilibrium by substituting (8) and (10) into the profit functions in (1)-(3), which are given as

$$
\begin{aligned}
\pi_{M}= & 1 *\left(\widetilde{Q}+\tau\left(\alpha_{r}-p_{r}^{*}+\gamma p_{m}^{*}+\alpha_{m}-p_{m}^{*}+\gamma p_{r}^{*}\right)\right)+w^{*}\left(\alpha_{r}-p_{r}^{*}+\gamma p_{m}^{*}\right) \\
& +(1-\delta)\left(p_{m}^{*}-c\right)\left(\alpha_{m}-p_{m}^{*}+\gamma p_{r}^{*}\right) \\
\pi_{E}= & \left(p_{r}^{*}-w^{*}\right)\left(\alpha_{r}-p_{r}^{*}+\gamma p_{m}^{*}\right)+\delta\left(p_{m}^{*}-c\right)\left(\alpha_{m}-p_{m}^{*}+\gamma p_{r}^{*}\right) \\
\pi_{T}= & \left(p_{m}^{*}-c\right)\left(\alpha_{m}-p_{m}^{*}+\gamma p_{r}^{*}\right)+p_{r}^{*}\left(\alpha_{r}-p_{r}^{*}+\gamma p_{m}^{*}\right) \\
& +1 *\left(\widetilde{Q}+\tau\left(\alpha_{r}-p_{r}^{*}+\gamma p_{m}^{*}+\alpha_{m}-p_{m}^{*}+\gamma p_{r}^{*}\right)\right) .
\end{aligned}
$$

Corollary 1. The wholesale price $w$ and the retail prices $p_{m}$ and $p_{r}$ all decrease with the spillover effect $\tau$.

Proof. Since $\quad(\partial w / \partial \tau)=-(1 / 2), \quad\left(\partial p_{m} / \partial \tau\right)=-\left(2-\gamma^{2} /\right.$ $\left.4(1-\delta)\left(1-\gamma^{2}\right)\right)$, and $\left(\partial p_{r} / \partial \tau\right)=-\left(\left(\gamma\left(2-\gamma-\gamma^{2}+\gamma \delta(1-\right.\right.\right.$ $\left.\delta))+(1-\gamma)(1-\delta)) /\left(4(1-\delta)\left(1-\gamma^{2}\right)\right)\right)$, one can obtain the results of Corollary 1 . The proof is complete.

Corollary 1 depicts the impacts of spillover effect on the optimal decisions of both the manufacturer and the e-tailer under the framework of static game. Results show that the manufacturer's optimal wholesale price $w$ decreases with the 
spillover effect $\tau$. Besides, as spillover effect increases, the manufacturer will markedly increase the sale quantities through the e-channels to simulate the offline sales. The intuition is that as the wholesale price $w$ and the retail prices decrease, the e-tailer will be more motivated to sell through online selling.

3.2. Dynamic Game. In this section, we focus on the dynamic game which captures the practical background that the manufacturer is boundedly rational and cannot know full information about the market. In this scenario, the bounded rationality will prevent the manufacturer from immediately reaching the Nash equilibrium in (8) and (9). Instead, the manufacturer will obtain the local maximum profit and reach the Nash equilibrium over time. Thus, the manufacturer updates her output next time $t+1$ on the basis of the expected marginal profit of the current period $t$. This means that the manufacturer will increase (decrease) her output in the next period if the marginal profit in the current period is positive (negative). This captures that the manufacturer will adjust her pricing decisions based on the local knowledge and estimation for the marginal profit in discrete time periods. Note that as compared to the manufacturer, the e-tailer often has more selling advantage and information. Thus, it is assumed that the e-tailer is fully rational.
And at each period $t$, once the manufacturer makes decisions on the prices $w(t)$ and $p_{m}(t)$, the e-tailer can optimally determine the retail price $p_{r}(t)$ under a static expectation to maximize his profit. Therefore, the optimal retail price can be identified as

$$
p_{r}(t+1)=\frac{1}{2}\left(\alpha_{r}+w(t)+\gamma p_{m}(t)+\delta \gamma\left(p_{m}(t)-c\right)\right) .
$$

At each time period $t$, the manufacturer adopts the myopic adjustment mechanism (e.g., $[34,35]$ ); that is,

$$
\begin{gathered}
w(t+1)=w(t)+\kappa_{w} w(t) \frac{\partial \Pi_{m}(t)}{\partial w(t)}, \\
p_{m}(t+1)=p_{m}(t)+\kappa_{p} p_{m}(t) \frac{\partial \Pi_{m}(t)}{\partial p_{m}(t)},
\end{gathered}
$$

where $\kappa_{w}$ and $\kappa_{p}$, respectively, denote the adjustment speeds of wholesale price and retail price and also represent the manufacturer's management behaviors. $\partial \Pi_{m}(t) / \partial w(t)$ and $\partial \Pi_{m}(t) / \partial p_{m}(t)$ are the marginal profits of the manufacturer at current period. If the marginal profits are equal to 0 , the prices $w(t+1)$ and $p_{m}(t+1)$ will not be modified further.

From (8)-(12), the dynamics of this game can be described by the following nonlinear dynamical system $T$ :

$$
T:\left\{\begin{array}{l}
w(t+1)=w(t)+\kappa_{w} w(t)\left((1-\delta) \gamma p_{m}(t)-w(t)+A_{1}\right), \\
p_{m}(t+1)=p_{m}(t)+\kappa_{p} p_{m}(t)\left((1-\delta)\left(\gamma^{2}(1+\delta)-2\right) p_{m}(t)+(1-\delta) \gamma w(t)+A_{2}\right),
\end{array}\right.
$$

where $A_{1}=(1 / 2)\left(\alpha_{r}+2 c \delta \gamma-\gamma c-\tau(1-\gamma)\right)$ and $A_{2}=$ $(\tau / 2)\left(\gamma^{2}(1+\delta)+\gamma(1-\delta)-2\right)+(1-\delta)\left((\gamma / 2)\left(\alpha_{r}-c \delta \gamma\right)+\right.$ $\left.\alpha_{m}-\left(\left(\gamma^{2} / 2\right)(1+\delta)-1\right) c\right)$.

In the following sections, we will analyze the dynamic behaviors of dynamic game system (14).

3.3. Equilibrium Points and Stability. The equilibrium of system (14) can be obtained as $w(t+1)=w(t)$ and $p_{m}(t+1)=p_{m}(t)$. The system has four equilibrium points as follows: $E_{0}=(0,0), E_{1}=\left(A_{1}, 0\right), E_{2}=\left(0,\left(A_{2} /((1-\delta)\right.\right.$ $\left.\left.\left.\left(2-\delta \gamma^{2}-\gamma^{2}\right)\right)\right)\right)$, and $E^{*}:=\left(w^{*}, p_{m}^{*}\right)=\left(\left(\left(A_{1}\left(2-\gamma^{2}(1+\right.\right.\right.\right.$
$\left.\left.\delta))+A_{2} \gamma\right) /\left(2\left(1-\gamma^{2}\right)\right)\right),\left(\left(A_{2}+A_{1} \gamma(1-\delta)\right) /(2(1-\delta)(1-\right.$ $\left.\left.\left.\gamma^{2}\right)\right)\right)$. Note that $E_{0}, E_{1}$, and $E_{2}$ are boundary equilibria, which is not in line with reality since the manufacturer will never adopt a zero price on $w$ or $p_{m}$. As a result, we only focus on $E^{*}$, which is the unique interior equilibrium of the two-dimensional dynamic system (14) and is also the static game equilibrium in the previous section. Next, we will explore the local stability of the fixed point $E^{*}$ by introducing the Jacobian matrix of the mapping (14) at the point $E^{*}$, which is given as

$$
J\left(E^{*}\right):=J\left(w^{*}, p_{m}^{*}\right)=\left(\begin{array}{cc}
1-\kappa_{w} w^{*} & (1-\delta) \gamma \kappa_{w} w^{*} \\
(1-\delta) \gamma \kappa_{p} p_{m}^{*} & 1+(1-\delta)\left(\gamma^{2}(1+\delta)-2\right) \kappa_{p} p_{m}^{*}
\end{array}\right)
$$

We further analyze the conditions for the local stability of the dynamic game equilibrium point $E^{*}$, which are shown in Proposition 1.

$$
\left\{\begin{array}{c}
\kappa_{p}(1-\delta) p_{m}^{*}\left(\gamma^{2}(1+\delta)+\left(1-\gamma^{2}\right) \kappa_{w} w^{*}-2\right)-\kappa_{w} w^{*}+2>0 \\
(1-\delta) \kappa_{p} p_{m}^{*}\left(\left(2-\gamma^{2}-\delta \gamma^{2}\right)-2 \kappa_{w}\left(1-\gamma^{2}\right) w^{*}\right)+\kappa_{w} w^{*}>0
\end{array}\right.
$$

Proposition 1. The equilibrium $E^{*}$ is locally asymptotically stable, when
Proof. The characteristic equation of the Jacobian matrix at $E^{*}$ is 


$$
\lambda^{2}-\operatorname{Tr}\left(J\left(E^{*}\right)\right) \lambda+\operatorname{Det}\left(J\left(E^{*}\right)\right)=0,
$$

where $\operatorname{Tr}\left(J\left(E^{*}\right)\right)$ and $\operatorname{Det}\left(J\left(E^{*}\right)\right)$, respectively, denote the trace and determinant of $J\left(E^{*}\right)$ and are given as

$$
\begin{aligned}
\operatorname{Tr}(J) & =2-\kappa_{w} w^{*}+\kappa_{p}(1-\delta)\left(\gamma^{2}(1+\delta)-2\right) p_{m}^{*}, \\
\operatorname{Det}(J) & =\kappa_{p} p_{m}\left(2 \kappa_{w}\left(1-\gamma^{2}\right) w-\left(2-\gamma^{2}-\delta \gamma^{2}\right)\right)-\kappa_{w} w+1, \\
\Delta & =\operatorname{Tr}\left(J\left(E^{*}\right)\right)^{2}-4 \operatorname{Det}\left(J\left(E^{*}\right)\right) .
\end{aligned}
$$

Moreover, the eigenvalues of the Jacobian matrix at $E^{*}\left(w^{*}, p_{m}^{*}\right)$ are $\lambda_{1,2}=\left(-\operatorname{Tr}\left(J\left(E^{*}\right)\right) \pm \sqrt{\Delta} / 2\right)$ when $\Delta \geq 0$ or $\lambda_{1,2}=\left(-\operatorname{Tr}\left(J\left(E^{*}\right)\right) \pm i \sqrt{-\Delta} / 2\right)$ when $\Delta<0$. Next, we examine the conditions under which the local asymptotical stability of the equilibrium $E^{*}$ can be guaranteed. According to Jury's stability criterion [36], the equilibrium is locally stable when the eigenvalues of $J\left(E^{*}\right)$ are inside the unit circle. Then, the coefficients of the characteristic polynomial of (17) satisfy the following conditions:

$$
\left\{\begin{array}{l}
1-\operatorname{Tr}(J)+\operatorname{Det}(J)>0 \\
1+\operatorname{Tr}(J)+\operatorname{Det}(J)>0 \\
1-\operatorname{Det}(J)>0
\end{array}\right.
$$

Note that the first condition $1-\operatorname{Tr}(J)+\operatorname{Det}(J)=$ $2 \kappa_{p} \kappa_{w} p_{m} w(1-\delta)\left(1-\gamma^{2}\right)>0$ can be naturally satisfied since $\gamma<1$ and $\delta<1$. The second condition is equivalent to $2\left(\kappa_{p}(1-\delta) p_{m}\left(\gamma^{2}(1+\delta)+\left(1-\gamma^{2}\right) \kappa_{w} w-2\right)-\kappa_{w} w+2\right)>0$. For the third condition, it can be transformed into $(1-\delta) \kappa_{p} p_{m}\left(\left(2-\gamma^{2}-\delta \gamma^{2}\right)-2 \kappa_{w}\left(1-\gamma^{2}\right) w\right)+\kappa_{w} w>0$. The proof is complete.

As mentioned above, the equilibrium $E^{*}$ is locally asymptotically stable only when the three inequalities in (19) hold simultaneously. According to the nonlinear dynamic system theory, the equilibrium will lose its stability if any one of them changes from an inequality to an equality with the other two remaining unchanged $[37,38]$. Therefore, these bifurcations exist: the system represents a transcritical, a fold (saddle-node), or a pitchfork bifurcation if $1-\operatorname{Tr}(J)+$ $\operatorname{Det}(J)=0$, which is excluded from the system parameter values in this paper; the stability is lost through a flip bifurcation if $1+\operatorname{Tr}(J)+\operatorname{Det}(J)=0$; otherwise, the stability is lost through a Neimark-Sacker bifurcation if $1-\operatorname{Det}(J)=0$. In other words, the three conditions, respectively, point to a transcritical, a fold (saddle-node), or a pitchfork bifurcation curve, flip bifurcation curve, and Neimark-Sacker bifurcation curve. Theoretically, the Neimark-Sacker bifurcation will destabilize the equilibrium, which essentially means that the stability of the system changes via a pair of complex eigenvalues within unit modulus. That also implies that both conditions $1-\operatorname{Det}(J)=0$ and $\Delta<0$ should be met together. In our model, the main parameters $\kappa_{w}$, $\kappa_{p}$, and $\tau$ are in the following region $\mathscr{P}=\left\{\left(\kappa_{w}, \kappa_{p}, \tau\right): 0<\kappa_{w}<1,0<\kappa_{p}<1,-\right.$ $1<\tau<1\}$, since empirical studies show that realistic values are in this range (see, e.g., $[7,10,39])$. In the simulation, the points $p \in \mathscr{P}$ which satisfy $1-\operatorname{Det}(J)=0$ but cannot meet $\Delta<0$. Thus, the Neimark-Sacker bifurcation is also excluded by the system parameter values in this work (e.g., $[40,41]$.

3.4. Dynamics Analysis. In this section, we plot the stability region, bifurcation diagrams, basin of attraction, and critical curve to investigate the dynamic behavior of system (14). We provide numerical evidences for the complex dynamical behaviors of system (14) when losing stability and show how the system evolves when the model parameters (mainly the adjustment speed $\kappa_{w}, \kappa_{p}$, agency fee $\delta$, and spillover parameter $\tau$ ) adopt different values. We set the basic parameters as follows: $\alpha_{r}=\alpha_{m}=10, \gamma=0.2, w(0)=6.02$, $p_{m}(0)=6.75$, and $c=1$. The simulated data used for carrying out the study are assumed to represent the real-world conditions as close as possible. Additionally, the data can ensure the existence of the equilibrium solution under full rationality.

First, we analyze the impacts of spillover effect on the stability. According to the Jury stability condition in (19), the $2 \mathrm{D}$ and $3 \mathrm{D}$ stable regions are depicted in Figure 1. If one of the four adjustment parameters is fixed, the stable condition can be plotted in a 3D space. Figure 1(a) shows the 3D stability region of the adjustment speeds $\left(\kappa_{w}, \kappa_{p}\right)$ and $\tau$ when $\delta=0.2$. If the values of $\left(\kappa_{w}, \kappa_{p}\right.$, and $\left.\tau\right)$ are in this region, system (14) will be stable at a fixed point; if any values of $\left(\kappa_{w}, \kappa_{p}\right.$, and $\tau$ ) do not belong to the $3 \mathrm{D}$ region, the system will lose its stability. In addition, Figure 1(b) reports the impacts of spillover effect on the system stability with $\tau$ taking various values and other parameter values remaining constant. As shown in Figure 1 that as $\tau$ increases, the intersection of the bifurcation curve with $\kappa_{w}$-axis moves rightwards and that with $\kappa_{p}$-axis moves upwards, which indicates that the size of the stability region increases in $\tau$. This implies that the increase in $\tau$ benefits the local stability of the dynamic system, and from a practical view, a greater spillover effect from online to offline sales pushes the "competition" business alliance towards a more coordinated outcome.

Furthermore, we analyze the effects of the agency fee on the stability. Similar to the spillover effect, the increase in the agency fee $\delta$ is more beneficial to the local stability of the dynamic system, as shown in Figure 2. The results show that the stable range of $\delta$ changes more in $\delta$ than that of $\tau$, which means that the agency fee has more influence on the stability than spillover effect. To show the dynamic behavior of this deterministic system when the equilibrium point loses its stability, we simulate the evolution process with respect to the wholesale price adjustment speed.

Figures 3 and 4 help to find the reciprocal effect of the wholesale price adjustment speed, spillover effect, and agency fee. Figure 3 shows the bifurcation phenomenon of pricing strategy in a $3 \mathrm{D}$ space with respect to the wholesale price adjustment speed $\kappa_{w}$ and $\tau$. The bifurcation graphs in red, green, and blue represent $\tau=-0.2, \tau=-0.1$, and $\tau=0.1$, respectively. With the increase of $\tau$, the value of $\kappa_{w}$ where the dynamic system (14) exhibits a period doubling bifurcation increases, which will give rise to a chaotic dynamic state. The increase of spillover effect expands the 

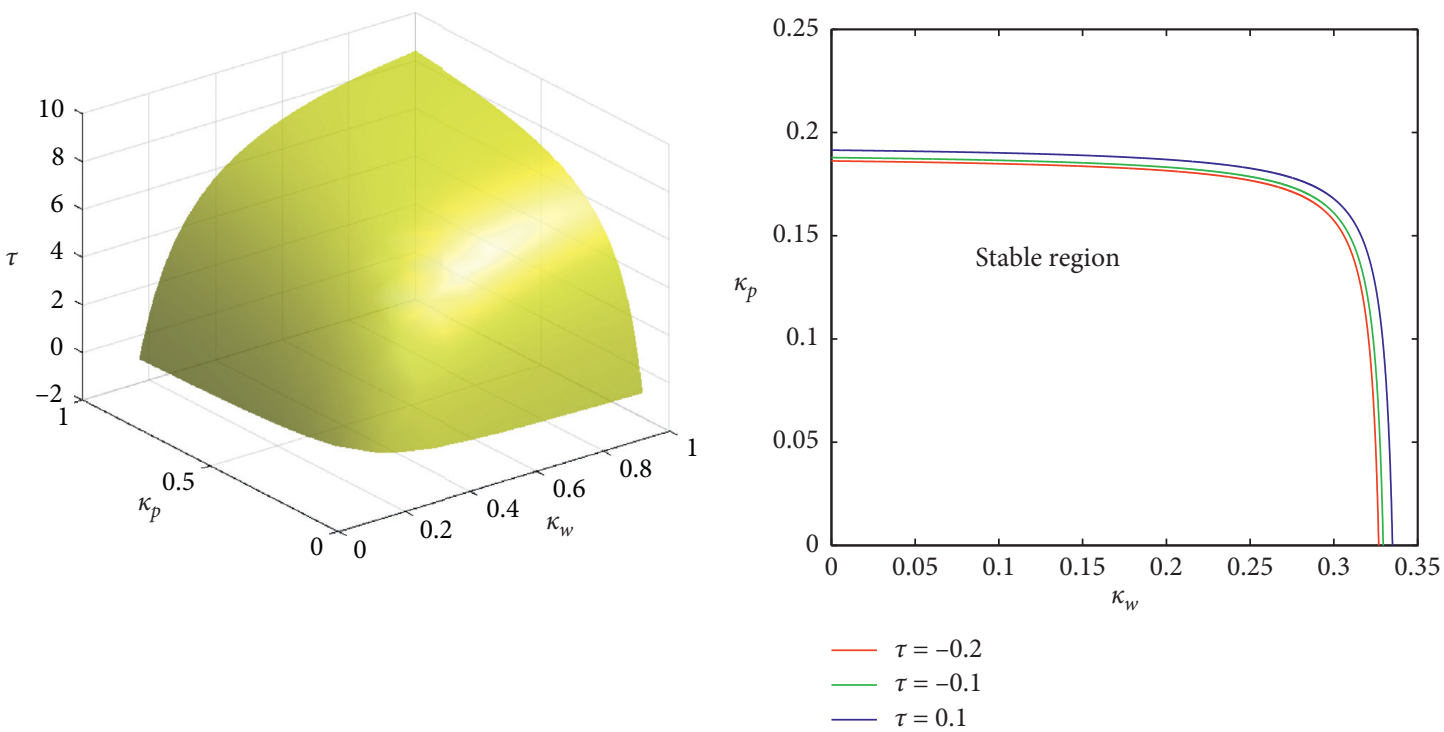

(a)

(b)

FIGURE 1: Stable region for adjustment speeds and $\tau$. (a) $3 \mathrm{D}$ stable region for $\kappa_{w}$, $\kappa_{p}$, and $\tau$, when $\delta=0.2$. (b) $2 \mathrm{D}$ stable region for $\kappa_{w}$ and $\kappa_{p}$, when $\delta=0.2$.

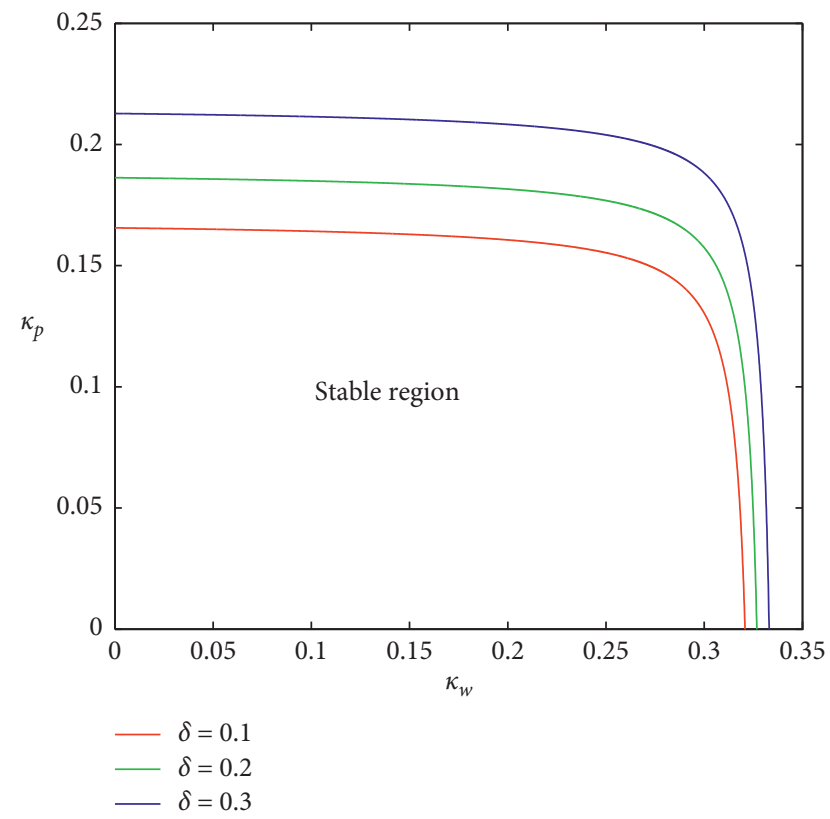

FIgURE 2: 2D stable region for $\kappa_{w}$ and $\kappa_{p}$, when $\tau=-0.2$.

stable range of the manufacturer's price adjustment speed, and the pricing decision system will enter into bifurcation and chaos later. This effect is mutual for the wholesale price and the agency selling price. Figure 4 also shows the bifurcation phenomenon in a $3 \mathrm{D}$ space with respect to the wholesale price adjustment speed $\kappa_{w}$ and $\delta$. The bifurcation graphs in red, green, and blue represent $\delta=0.1$, $\delta=0.2$, and $\delta=0.3$, respectively. Similarly, with the increase of $\delta$, the value of $\kappa_{w}$ where chaos occurs also increases. It can be concluded that the increase of the agency fee enlarges the stable range of the manufacturer's price adjustment speed, and the pricing decision system will lose its stability later.

In order to further study the impacts of the adjustment speeds on the system, the overall system decision-making situation is shown through $2 \mathrm{D}$ bifurcation diagram as in Figure 5. In Figure 5, different colors are used to represent stable cycles of different periods. We assign different colors to stable steady states (red); stable cycles of periods 2 (blue), 4 (purple), and 3 (green); chaos (white); and divergence (black). The stable region in Figure 5 is the same as that in Figure 1(b), where the manufacturer's decisions have the same stable region according to Proposition 1. Besides, with the adjustment speeds increasing, the system goes into chaos through period doubling and finally disappears. Over high adjustment, speeds for the manufacturer do not benefit the system's stability, which is shown clearly in the figures. By comparing the sizes of stable regions, we can see the different capacity of the models for maintaining the system stability. Figures $5(\mathrm{a})-5(\mathrm{~d})$ all show that spillover effect benefits the system's stability.

The above analysis of bifurcation and chaos provides some managerial insights into pricing, spillover effect, and agency fee. The increase of any adjustment speed may make the system from a stable state to a periodic state or a chaotic state, causing the decision variables to suffer from a large fluctuation. However, a higher agency fee and higher spillover effect bring more price adjustment space.

3.5. Global Analysis. In the previous section, we limit the scope of local analysis to a small neighborhood near the equilibrium point. Nevertheless, because of the manufacturer's subjective judgement of the market under limited information at the beginning of the game, the initial values of the state variables (i.e., the initial pricing strategies) may not belong to such a neighborhood. As a result, it is 


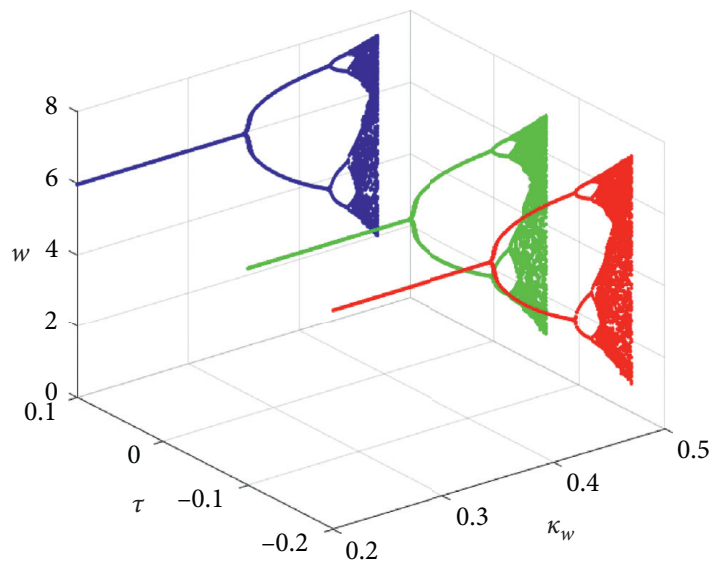

(a)

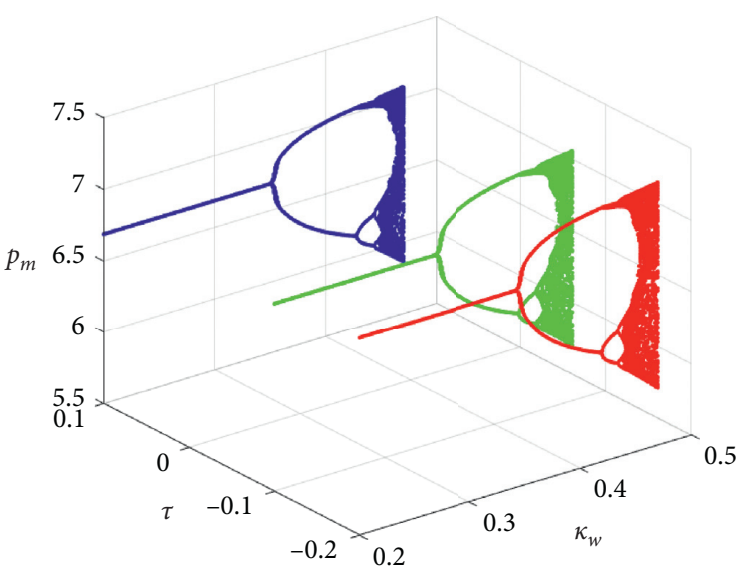

(b)

FIgURE 3: 3D bifurcation diagrams of $w$ in (a) and $p_{m}$ in (b) with respect to $\kappa_{w}$ and $\tau$, when $\kappa_{p}=0.14$ and $\delta=0.2$.

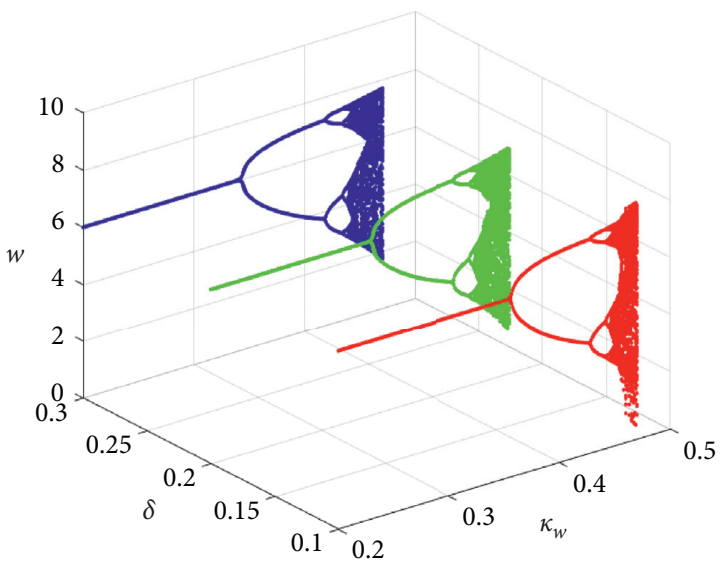

(a)

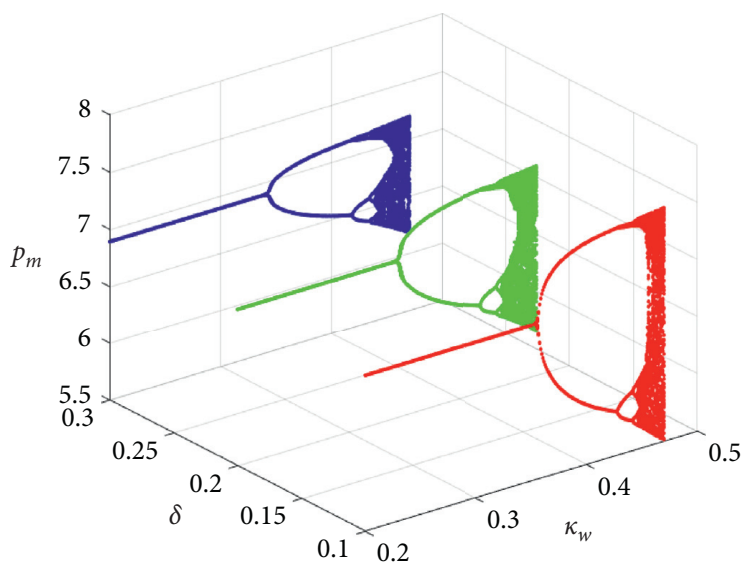

(b)

Figure 4: 3D bifurcation diagrams of $w$ in (a) and $p_{m}$ in (b) with respect to $\kappa_{w}$ and $\delta$, when $\kappa_{p}=0.14$ and $\tau=-0.2$.

significant to apply the global analysis method, which has been widely proposed by some previous researches, such as Mira et al. [42]; Agliari et al. [43]; Andaluz and Jarne [44]; Bischi and Kopel [45]; and Bischi et al. [46] to explore the long-run behaviors of the dynamic game system (14). In this study, a flip (period doubling) bifurcation will destabilize the equilibrium, which essentially means that the stability of the system changes via a real eigenvalue -1 . Thus, there is a fliptype bifurcation that can produce periodic and chaotic attractors around the unstable equilibrium. In the following, we will focus on three important concepts belonging to the global dynamics in a two-dimensional noninvertible mapping, i.e., attractors, critical curves, and basins of attraction, to analyze the equilibrium from the perspective of global dynamics.

The role of a basin of attraction is to serve as a guideline, which can ensure that the initial pricing strategies belonging to the domain of the attraction converge to the same attractor. For better illustration, Figure 6 shows the basin of attraction for the dynamic game system (14). Note that the dynamic process has practical significance only when the condition $S=\left\{\left(w, p_{m}\right) \in R^{2}: w>0, p_{m}>0\right\}$ is satisfied, and this is worth further studying. If we define system (14) as a mapping $T$, which is noninvertible, then the rank-1 preimage may not exist or may be multivalued for a given $\left(w(t+1), p_{m}(t+1)\right)$. As the point $\left(w(t+1), p_{m}(t+1)\right)$ varies in the plane $S$, the number of solutions of system (14), i.e., the number of the rank-one preimages of $\left(w(t+1), p_{m}(t+1)\right)$, changes. Pairs of real preimages appear or disappear as the points $\left(w(t+1), p_{m}(t+1)\right)$ cross the boundary separating regions whose points have a different number of preimages. Such boundaries generally characterized by the presence of two merging preimages are called critical curves. The critical curves are defined as the locus of points having two or more coincident rank-1 preimages. LC is the two-dimensional generalization of the notion of critical value (local minimum of maximum value), which means that critical curves may be used in order to bound chaotic attractors or in order to detect global bifurcations that cause a qualitative change in the topological structure of basins of attraction, such as the creation of nonconnected basins (e.g., [42, 45, 47, 48]). To be specific, 


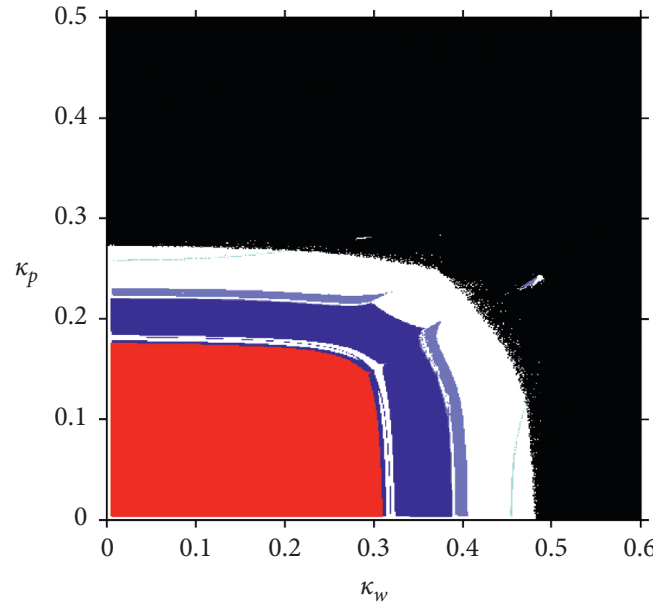

(a)

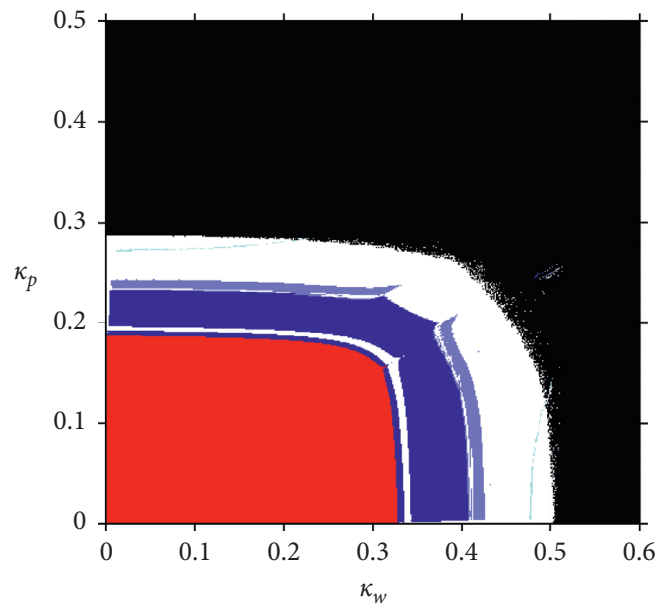

(c)

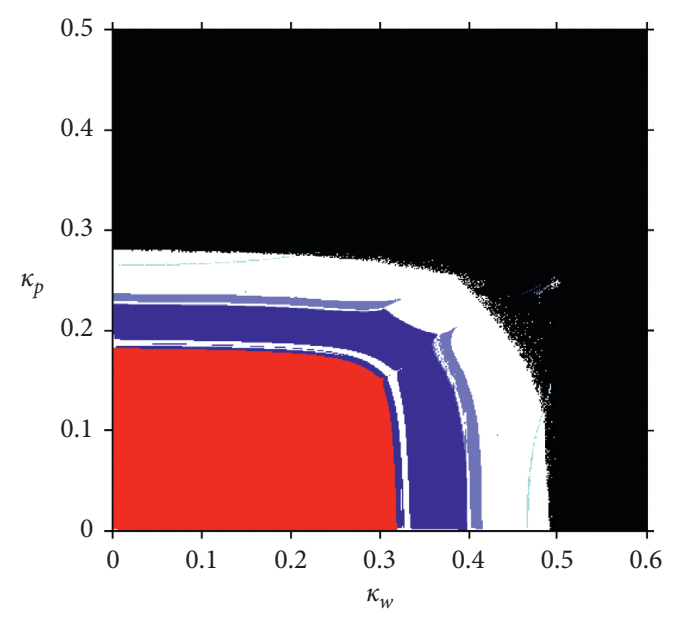

(b)

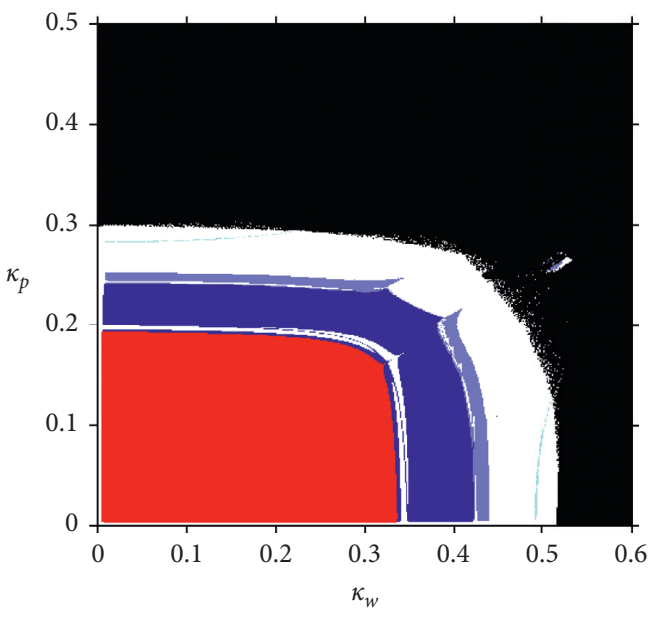

(d)

FIGURE 5: 2D bifurcation diagrams with respect to $\kappa_{w}$ and $\kappa_{p}$, under different $\tau$. (a) $\tau=-0.5$. (b) $\tau=-0.2$. (c) $\tau=0.1$. (d) $\tau=0.5$.

due to the binary quadratic character of the system, there is a fourth-degree algebraic equation with no, two, or four solutions when we solve $\left(w(t), p_{m}(t)\right)$ by means of $(w(t+$ $\left.1), p_{m}(t+1)\right)$ in the mapping $T$. The direct result is that the space of $R^{2}$ is divided into different regions, which are represented by $Z_{i}$ ( $i$ being the number of rank-1 preimages) and are specified by some boundaries composed of at least two preimages. For instance, $\left(w(t), p_{m}(t)\right)$ in region $Z_{2}$ has 2 preimages $\left(w(t-1), p_{m}(t-1)\right)$. In Figure 6, the symbols $Z_{0}, Z_{2}$, and $Z_{4}$ refer to the 0 -, 2 -, and 4 -solution regions, respectively. It is intuitive to find that the region is divided into three parts with two critical curves $\mathrm{LC}^{(a)}$ and $\mathrm{LC}^{(b)}$. Next, we will introduce another curve represented by $\mathrm{LC}_{-1}$, which is the rank-1 preimage of $L C$ under $T$, i.e., $T\left(\mathrm{LC}_{-1}\right)=\mathrm{LC}$, to obtain the critical curve LC. When the Jacobian determinant of $T$ vanishes, the curve $L_{-1}$ generally belongs to the locus of points; that is,

$$
\mathrm{LC}_{-1} \subseteq\left\{\left(w, p_{m}\right): \operatorname{Det}(J)\left(w, p_{m}\right)=0\right\} .
$$

Note that the curve $\mathrm{LC}_{-1}$ can be defined as a function of $\left(w, p_{m}\right)$ when the parameters $\kappa_{w}, \kappa_{p}$, and $\delta$ are fixed. We find that $\mathrm{LC}_{-1}$ is a hyperbola with two branches represented by
$\mathrm{LC}_{-1}^{a}$ and $\mathrm{LC}_{-1}^{b}$, respectively. And $\mathrm{LC}$ is the union of two branches denoted as $\mathrm{LC}^{a}=T\left(\mathrm{LC}_{-1}^{a}\right)$ and $\mathrm{LC}^{b}=T\left(\mathrm{LC}_{-1}^{b}\right)$.

Figure 6 depicts the evolution process of the attractors (red dot) and basins of attractors (green region), where the red dotted curves and blue solid curves stand for $\mathrm{LC}_{-1}$ and LC, respectively. Some conclusions can be obtained by comparing Figures 6(a)-6(d). First of all, it is obvious to observe that when the wholesale price adjustment speed gets larger, the attractor becomes more complex and its basins shrink. Besides, the system will be more easier to collapse as the wholesale price adjustment speed increases. To be more specific, with a relatively small wholesale price adjustment speed as shown in Figure 6(a), the attractor is a single point set, which corresponds to a global asymptotically stable equilibrium. As the wholesale price adjustment speed increases as shown in Figure 6(b), the attractor turns to be the set with only two elements, corresponding to a two-period cycle. When the wholesale price adjustment speed is large enough, as depicted in Figures 6(c) and 6(d), the sets with uncountable elements which correspond to chaotic attractors will occur. From Figure 6, we can observe that the LC curves constitute the boundary (or the envelope) of the attractor. 


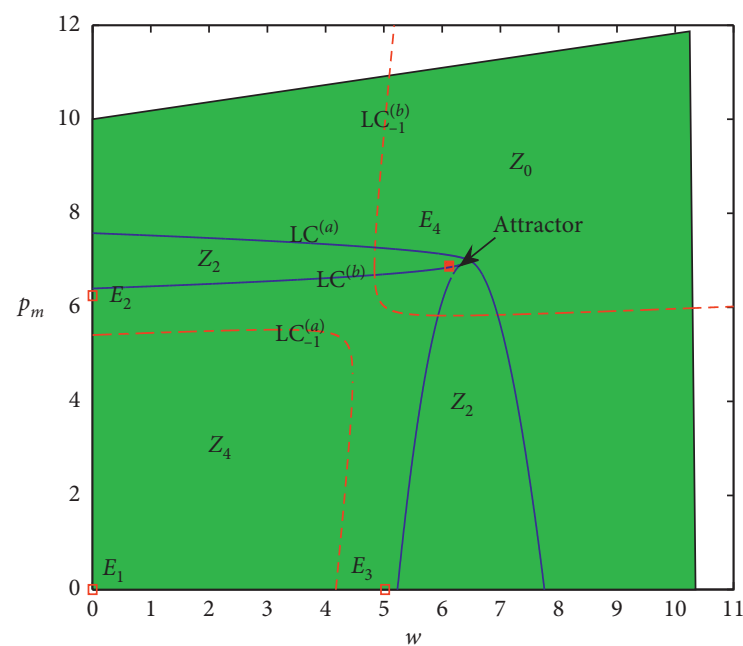

(a)

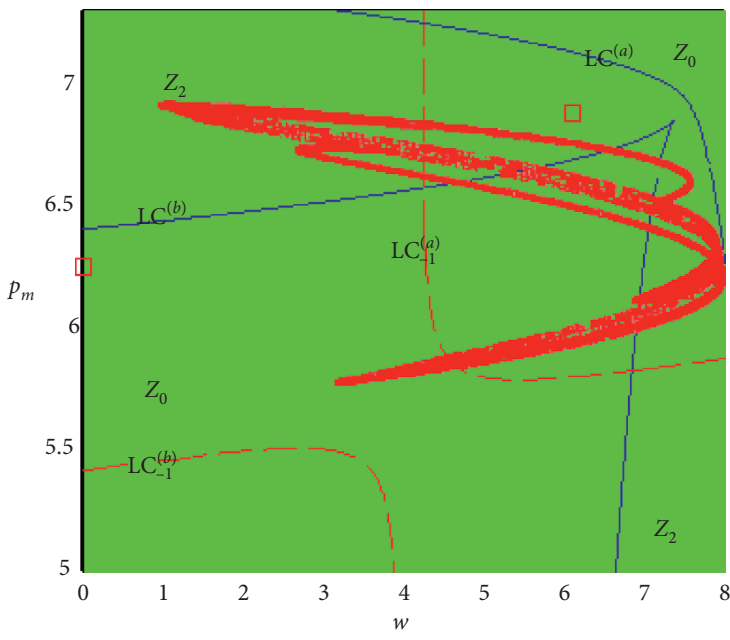

(c)

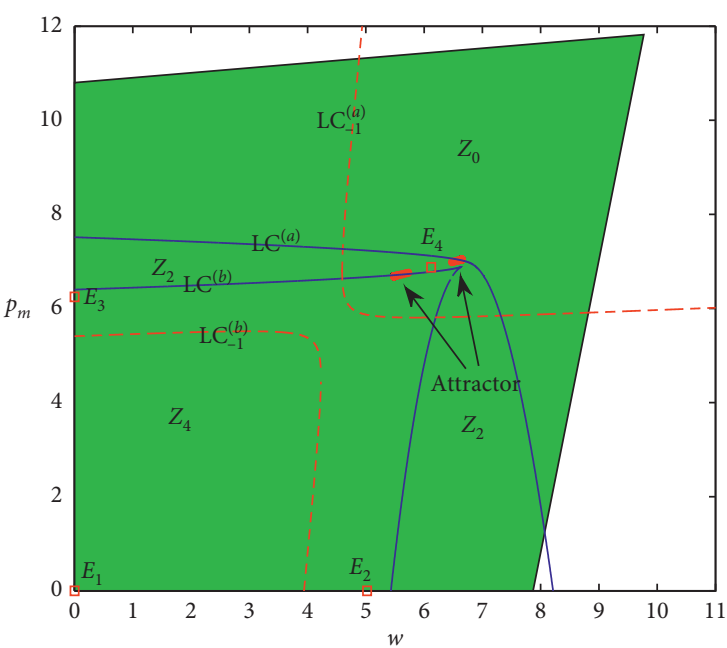

(b)

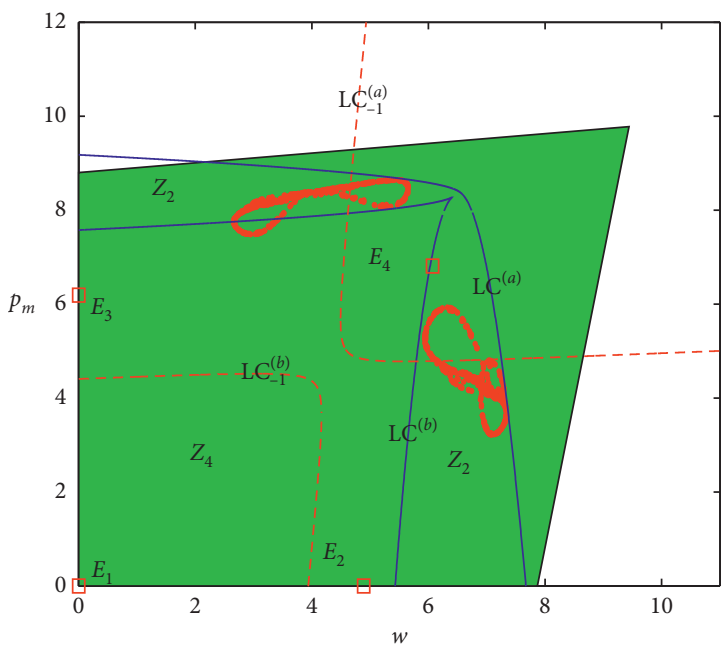

(d)

FIgURE 6: Attractors (red dot) and basins of attractors (green region) where $\mathrm{LC}^{a}$ and $\mathrm{LC}^{b}$ are represented by blue solid line, and $\mathrm{LC}_{-1}^{a}$ and $\mathrm{LC}_{-1}^{b}$ are represented by red dotted line when $\delta=0.2$. These curves of LC separate the plane into three regions, denoted by $Z_{4}, Z_{2}$, and $Z_{0}$ whose points have four, two, and no rank-1 preimages, respectively. (a) $\kappa_{w}=0.3, \kappa_{p}=0.14, \tau=-0.2$. (b) $\kappa_{w}=0.35, \kappa_{p}=0.14, \tau=-0.2$. (c) $\kappa_{w}=0.455, \kappa_{p}=0.14, \tau=-0.2$. (d) $\kappa_{w}=0.35, \kappa_{p}=0.25, \tau=-0.1$

To verify that an observable chaos occurs for such values of $\kappa_{w}$ and $\kappa_{p}$ in Figures 6(c) and 6(d). We plot the Largest Lyapunov Exponent (LLE) in the interval $\kappa_{w} \in[0.454$, 0.4555]. As LLE $>0$, the mapping exhibits an observable chaos in the sense that it has attractors. That means that the system is in chaotic state. From Figure 7, it can be seen that LLE $>0$ when $\kappa_{w}=0.455$. This means that the red attractors in Figure 6(c) are chaotic attractors. For the attractors in Figure 6(d), we have made a verification similar to Figure 6(c), and thus the details are omitted here.

The time series corresponding to Figure 6 are described in Figure 8, where the blue series and the red series stand for retail price $p_{m}$ and wholesale price $w$, respectively. As shown in Figure 8(a), the system converges to the equilibrium point after a few periods when the adjustment speed is relatively low. In other words, the pricing strategies of the dynamic

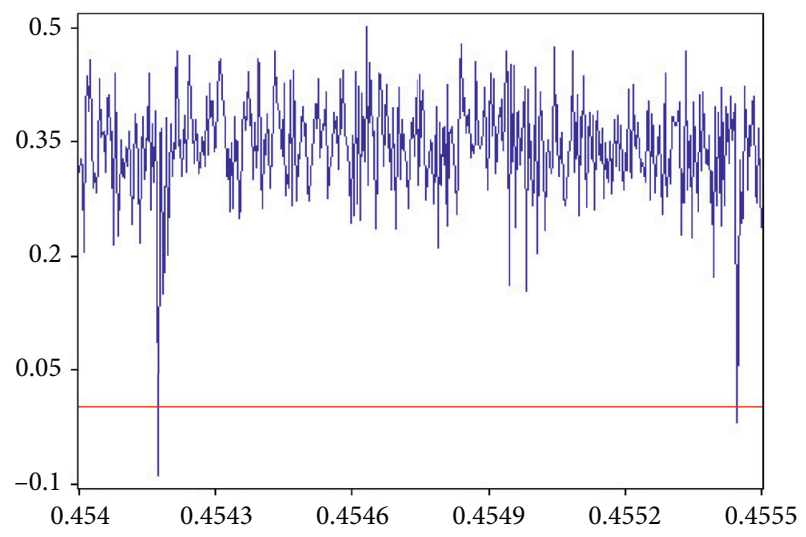

FIGURE 7: LLE with respect to $\kappa_{w}$ in $[0.454,0.4555]$, with $\kappa=0.14$ and $\tau=-0.2$. 


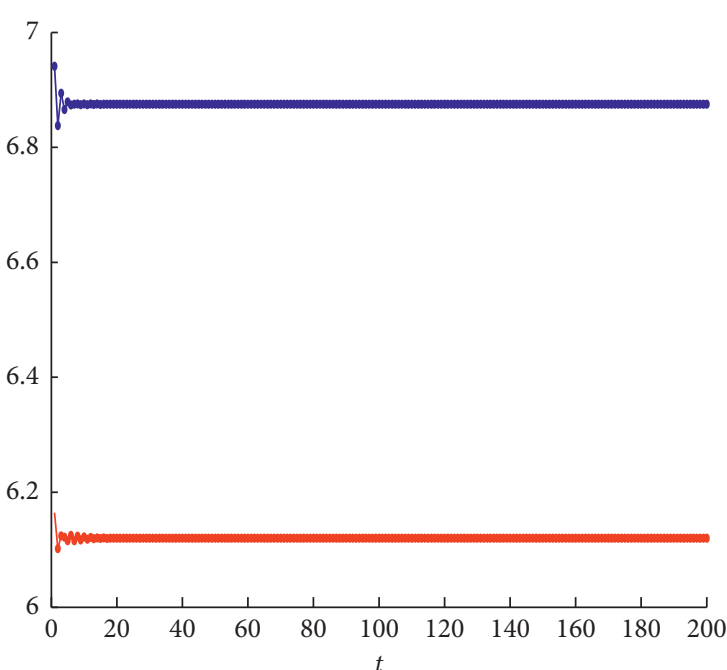

(a)

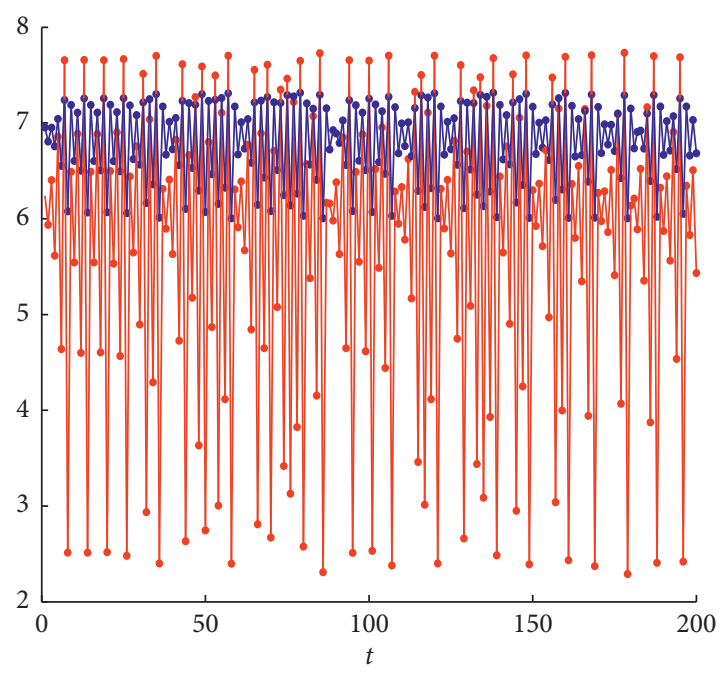

(c)

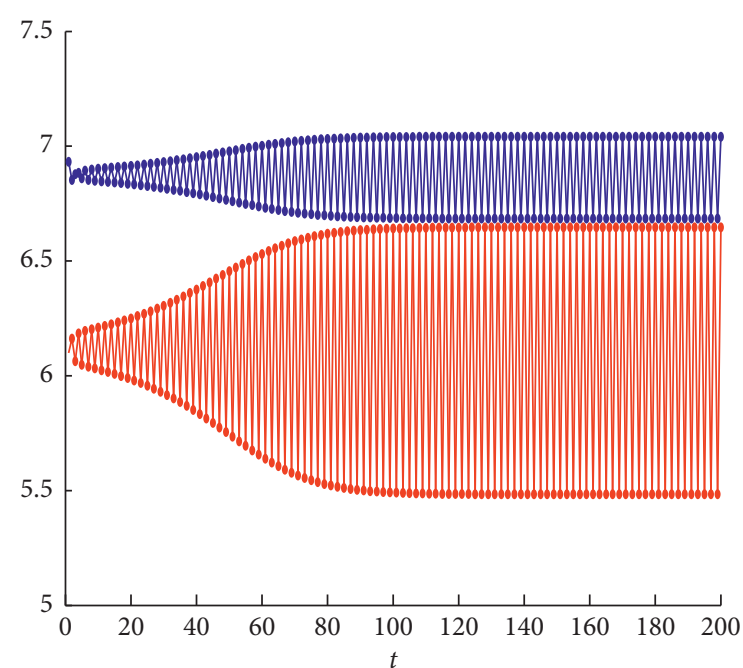

(b)

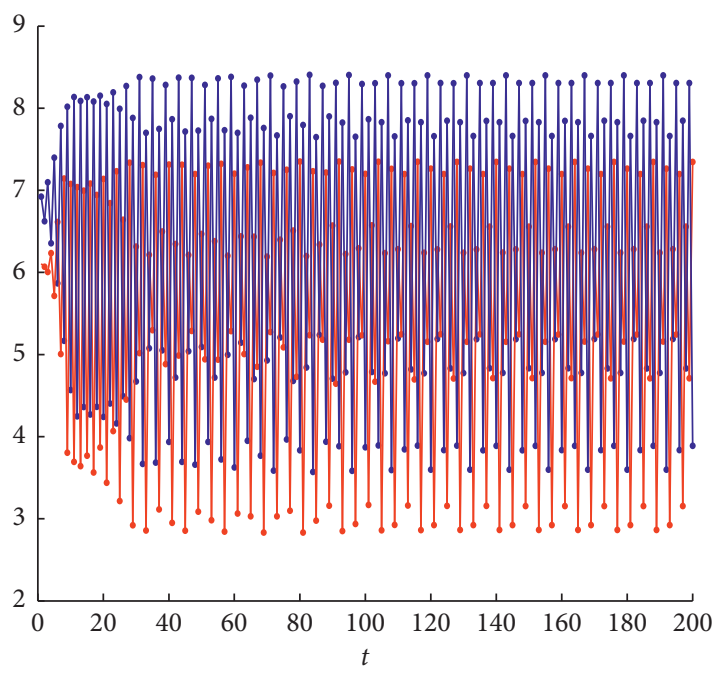

(d)

Figure 8: Time series of $w$ (red dot) and $p_{m}$ (blue dot) corresponding to Figure 6. (a) $\kappa_{w}=0.3, \kappa_{p}=0.14, \tau=-0.2$. (b) $\kappa_{w}=0.35, \kappa_{p}=0.14, \tau=-0.2$. (c) $\kappa_{w}=0.445, \kappa_{p}=0.14, \tau=-0.2$. (d) $\kappa_{w}=0.35, \kappa_{p}=0.25, \tau=-0.1$.

repeated game will eventually converge to the same equilibrium state as that of the static one-shot game. As shown in Figure 8(b), the evolution trajectory becomes periodic as the wholesale price adjustment speed increases, meaning that the prices are adjusted periodically. Furthermore, as shown in Figures 8(c) and 8(d), the chaos will occur when the wholesale price adjustment speed gets even higher. Under this situation, the prices over time are irregular, which rely on the initial strategy values sensitively. As a consequence, it is difficult for the manufacturer to implement stable longterm pricing strategies, indicating that the manufacturer should set the wholesale price adjustment speed carefully. Note that in the case of chaos, the manufacturer takes irregular and unpredictable pricing strategies with the wholesale price $w$ being "randomly" larger or smaller than the agency selling price $p_{m}$, which leads to a "randomly" larger or smaller retail price $p_{r}$ as compared to the agency selling price $p_{m}$.
3.6. Performance Comparison. This section investigates the effects of critical parameters on the supply chain members' profits and further compares the performance of the dynamic game with that of the static game. It should be noted that the game process may evolve to complex dynamics including periodic or chaotic state under the dynamic game, meaning that the profits of the supply chain members are generally unpredictable. As a consequence, we need to calculate the average profits to make a further comparison. To reach the goal, we adopt $10^{3}$ game outcomes (strategy points) in the chaotic attractor and set the initial strategies randomly. The initial strategies should ensure the existence of the game equilibria under full rationality, and we find this initial strategy values will not essentially affect the members' profits. Figures 9 and 10 depict the performances of the dynamic repeated game and the static one-shot game intuitively, which are denoted by the solid curves and the dotted lines, respectively. Besides, in both figures, the profits 


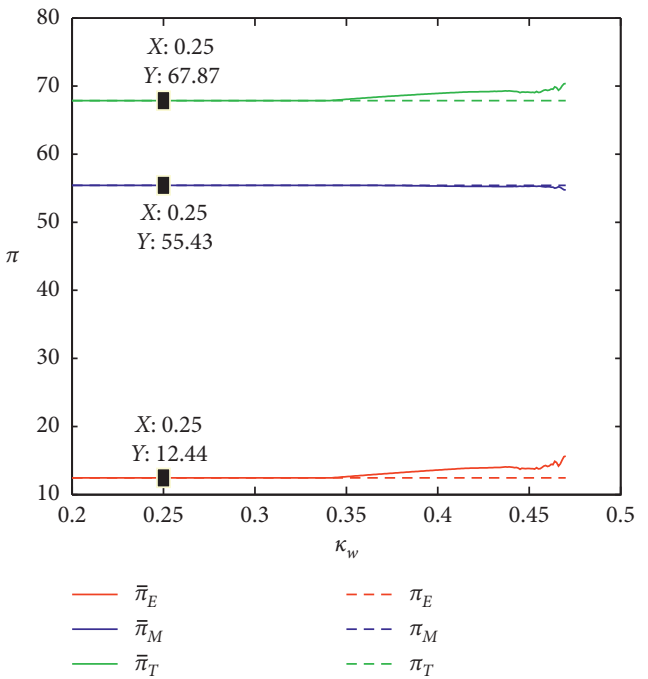

(a)
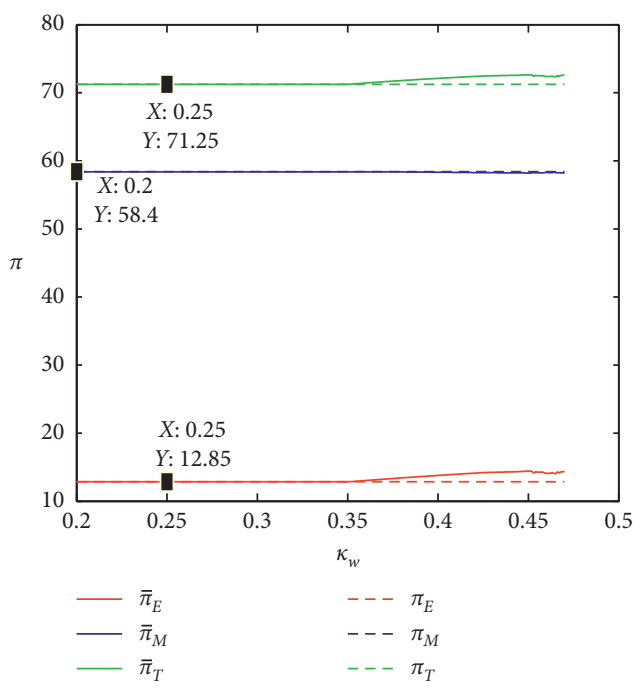

(c)

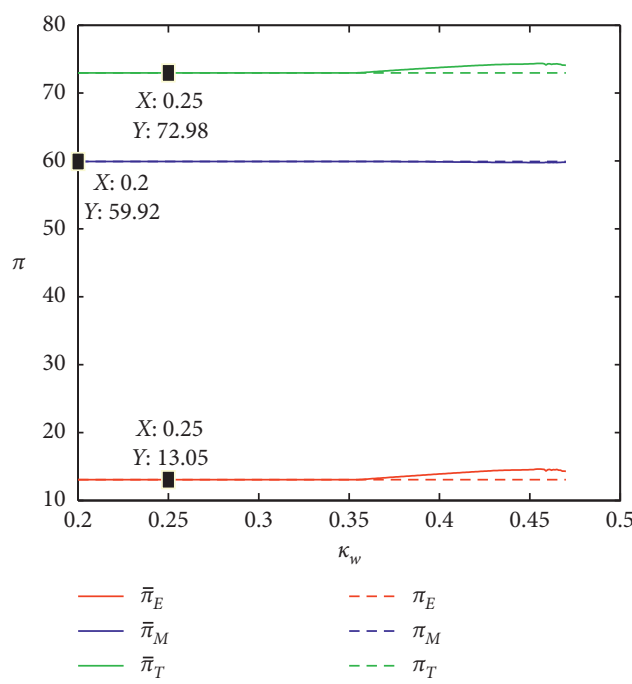

(e)

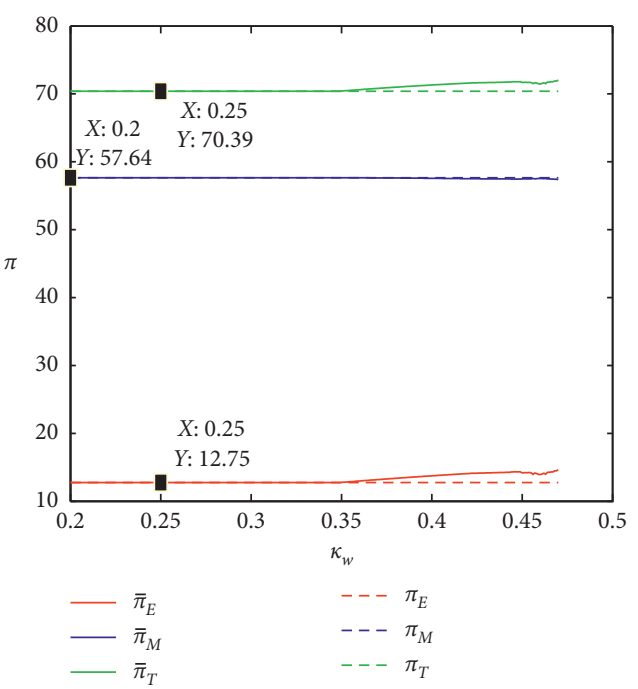

(b)

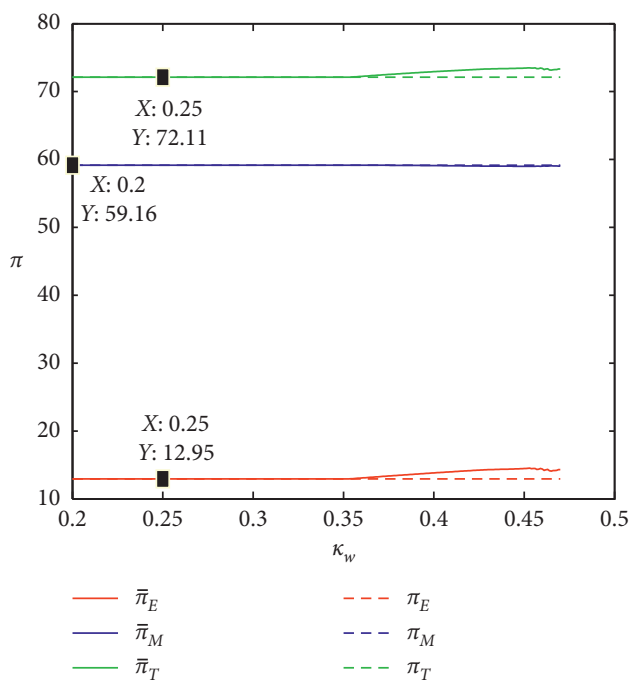

(d)

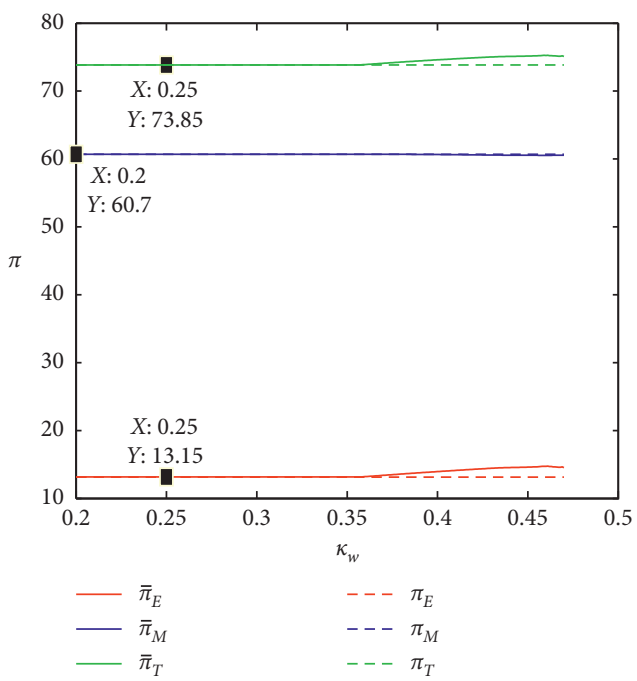

(f)

Figure 9: Supply chain members' average profits via $\kappa_{w}$ under different $\tau$. (a) $\tau=-0.4$. (b) $\tau=-0.1$. (c) $\tau=0$. (d) $\tau=0.1$. (e) $\tau=0.2$. (f) $\tau=0.3$. 


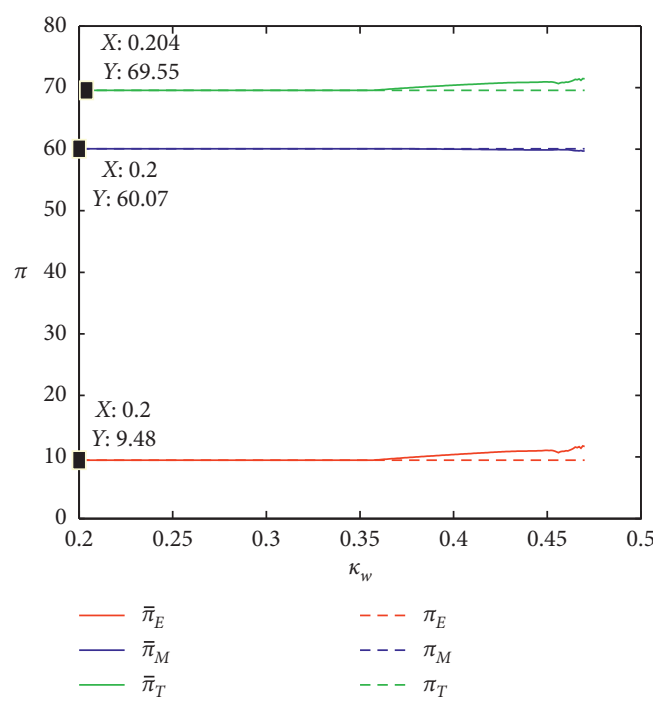

(a)

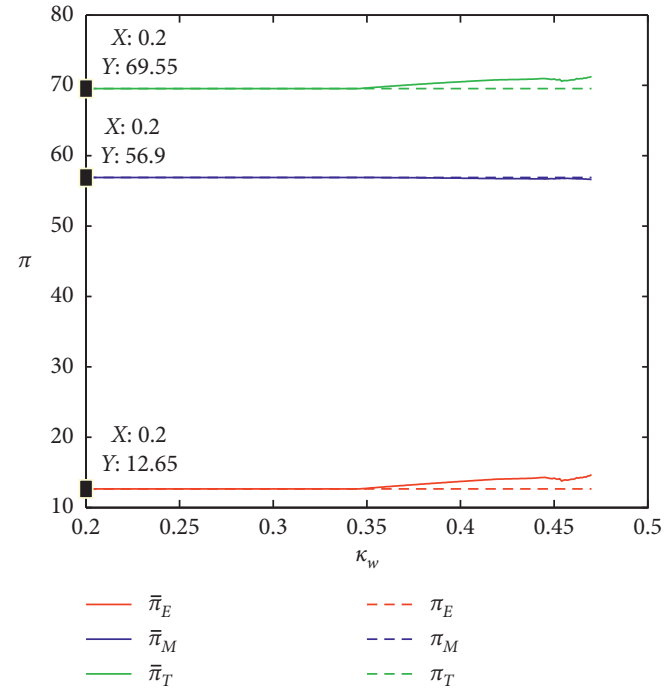

(b)

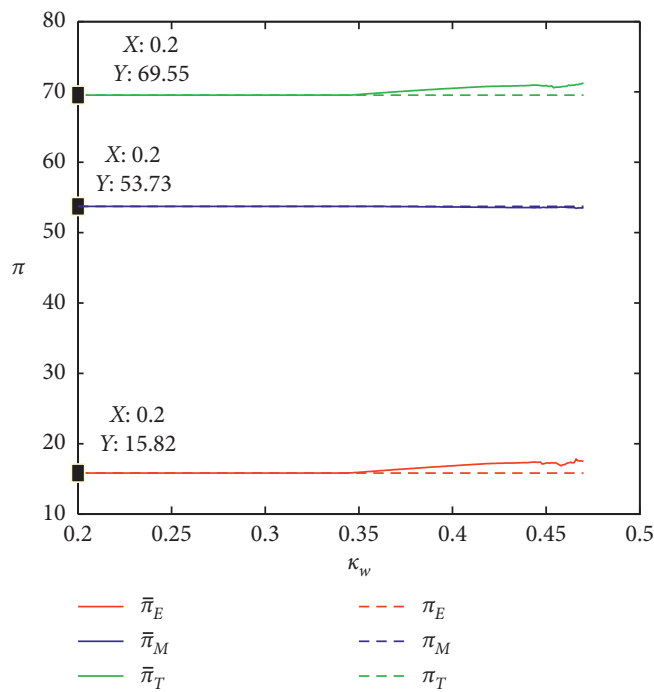

(c)

FIGURE 10: Supply chain members' average profits via $\kappa_{w}$ under different $\delta$. (a) $\delta=0.1$. (b) $\delta=0.2$. (c) $\delta=0.3$.

of the total supply chain, the manufacturer, and the e-tailer are represented by the green lines, blue lines, and red lines, respectively. Note that we have carried out a large number of numerical examples to verify that the main results would not be influenced qualitatively by the various values of the parameters, which demonstrates that the results are robust.

Figure 9 shows the effects of the manufacturer's wholesale price adjustment speed on the members' and the supply chain's profits for different spillover effect levels. When the system converges to the equilibrium point, the total average profits of the members in the dynamic game are not sensitive to the wholesale price adjustment speed and are the same as those in the static one-shot game. However, when the system is in periodic or chaotic state, the total average profits of the manufacturer and the e-tailer will change. To be specific, as the wholesale price adjustment speed increases, the average profit of the manufacturer in the dynamic game is almost the same as that in the static game. While for the e-tailer, his average profit will climb up as the wholesale price adjustment speed increases. From the perspective of the whole supply chain, the average profit in the dynamic game increases with the wholesale price adjustment speed and is higher than the profit in the static game. Moreover, by comparing Figures 9(a)-9(f), it is clearly observed that spillover effect has a significant effect on the total average profit, i.e., a higher spillover effect makes the average profits of the members and the whole supply chain increase in the dynamic game, which demonstrates that spillover effect benefits the supply chain performance.

Figure 10 characterizes the effects of the agency fee $\delta$ on the profits of the members and the supply chain under both the dynamic and static games. First, the effect of the adjustment speed $\kappa_{w}$ on average profits in Figure 10 is similar to that in Figure 9, and thus we will not repeat it. By 
comparing Figures $10(a)-10(c)$, we find that a higher agency fee will harm the manufacturer but benefit the e-tailer. From the perspective of the whole supply chain, its efficiency will not essentially change with the agency fee.

The joint observations of Figures 9 and 10 show that as compared to the outcomes under the equilibrium strategy in the static game, the e-tailer's profit in the repeated game is always higher, and the manufacturer's profit is identical. This implies that bounded rationality can mitigate the competition between the two members and encourage the e-tailer to introduce the agency selling channel. Particularly, a winwin outcome occurs in a certain interval of $\kappa_{w}$ as presented where the whole supply chain's profit in the dynamic game is higher than the equilibrium profit in the static game. This dynamic pricing process provided by the manufacturer can effectively encourage the e-tailer to participate in multichannel selling, which is different from the common conclusion that the equilibrium profit in the static game is the first-best outcome (e.g., [10]).

\section{Conclusion}

With the rapid development of e-commerce, upstream manufacturers often cooperate with e-tailers to sell their products in two online modes (reselling and agency selling modes) in addition to the traditional offline channel (i.e., the brick-and-mortar channel), and the multichannel supply chain structure is a common setting in practice. The introduction of multi-online channels is inevitably accompanied by spillover effect; that is, the sales in the offline channel are affected by the sales in the online channels. The spillover effect which can stimulate offline demand or decrease offline demand (the cannibalization effect) will significantly affect pricing strategies in the supply chain. This paper incorporates the spillover effect from online to offline sales into the pricing game in a multichannel supply chain. In this study, combined with the spillover effect, we mainly focus on a dynamic repeated game process for the decision makers with bounded rationality, which is different from the existing researches with the assumption of fully rational players. By virtue of the nonlinear system theory, we investigate the impacts of critical system parameters (such as the level of spillover effect, the adjustment speed, and the agency fee) on the stability, complexity, and efficiency of the dynamic game system.

Some meaningful conclusions emerge after solving and analyzing the model. First, the stability of the dynamic system depends on the wholesale price adjustment speed. When this adjustment speed is relatively low, the dynamic strategies will converge to a static equilibrium point under certain conditions. While as the adjustment speed increases, the attractor of the game system becomes more complex, leading to chaos eventually. Besides, although an excessively high adjustment speed can destabilize the dynamic system, the e-tailer can benefit from this instability, and so as the whole supply chain. The agency fee and the spillover effect have similar effects on the dynamic system, and the system will become more stable if either of them increases. Furthermore, the spillover effect has less impact on the stability of the dynamic system than the agency fee.

Although some important findings and interesting managerial insights are provided in the paper, there are also some limitations as follows. In this study, we only consider that the manufacturer is a local profit maximizer (bounded rationality) but the e-tailer acts as a global profit maximizer (full rationality). In some practical cases, the e-tailer may also be a local profit maximizer with bounded rationality. Thus, it is of great significance to further explore firms' dynamic pricing strategies considering both chain members' actions under bounded rationality and provide more reasonable operational decisions for firms. In addition, we only focus on the pricing policy in a supply chain and omit the other operational or marketing policies. It may be interesting to include quality improvement or retail service investment policies into the research.

\section{Data Availability}

The data used to support the findings of this study are included within the article.

\section{Conflicts of Interest}

The authors declare that there are no conflicts of interest regarding the publication of this paper.

\section{Acknowledgments}

This work was supported by the National Natural Science Foundation of China (no. 71971152).

\section{References}

[1] eMarketer, Worldwide Retail and Ecommerce Sales: Emarketer's Updated Forecast and New Mcommerce Estimates for 2016-2021, eMarketer, New York City, NY, USA, 2018, https:// www.emarketer.com/Report/Worldwide-Retail-EcommerceSales-eMarketers-Updated-Forecast-New-McommerceEstimates-20162021/2002182.

[2] M. Bonfils, "Taobao SEO: a guide to one of the world's largest consumer marketplaces," 2012, http://searchenginewatch. com/article/2200749/Taobao-SEO-A-Guide-to-One-of-theWorlds-Largest-Consumer-Marketplaces.

[3] A. Tiwari, "Flipkart to grow marketplace to compete with amazon. DNA India," 2014, http://www.dnaindia.com/ money/report-?ipkart-to-grow-marketplace-to-competewith-amazon-1979084.

[4] CKGSB, Will Ecommerce Replace Brick-ortar-hinese-etailers?, CKGSB, Beijing, China, 2017, http://knowledge.ckgsb.edu.cn/ 2017/02/27/retail/will-ecommerce-replace-brick-mortar-chineseretailers/.

[5] C. Daily, "Xiaomi releases mi 6, speeds up offline expansion," 2017, http://m.chinadaily.com.cn/en/2017-04/19/content_ 28999144.htm.

[6] CNET, Xiaomi's Move into Brick-and-Mortar Stores has Paid Off, CNET, San Francisco, CA, USA, 2017, https://www.cnet. com/news/xiaomi-hits-its-highest-ever-phone-shipmentsfor-q2/.

[7] V. Abhishek, K. Jerath, and Z. J. Zhang, "Agency selling or reselling? Channel structures in electronic retailing," Management Science, vol. 62, no. 8, pp. 2259-2280, 2015. 
[8] Y. Yan, R. Zhao, and T. Xing, "Strategic introduction of the marketplace channel under dual upstream disadvantages in sales efficiency and demand information," European Journal of Operational Research, vol. 273, no. 3, pp. 968-982, 2019.

[9] F. Zhang and C. Wang, "Dynamic pricing strategy and coordination in a dual-channel supply chain considering service value," Applied Mathematical Modelling, vol. 54, pp. 722-742, 2018.

[10] J. Ma and L. Xie, "The comparison and complex analysis on dual-channel supply chain under different channel power structures and uncertain demand," Nonlinear Dynamics, vol. 83, no. 3, pp. 1379-1393, 2016.

[11] Z. Guo, "Complexity and implications on channel conflict under the uncertain impacts of online customer reviews," Nonlinear Dynamics, vol. 96, no. 3, pp. 1971-1987, 2019.

[12] J. Ma, T. Li, and W. Ren, "Research on the complexity of dualchannel supply chain model in competitive retailing service market," International Journal of Bifurcation and Chaos, vol. 27, no. 7, Article ID 1750098, 2017.

[13] A. Naimzada and M. Pireddu, "Fashion cycle dynamics induced by agents' heterogeneity for generic bell-shaped attractiveness functions," Journal of Difference Equations and Applications, vol. 25, no. 7, pp. 942-968, 2019.

[14] A. Naimzada and M. Pireddu, "Eductive stability may not imply evolutionary stability in the presence of information costs," Economics Letters, vol. 186, Article ID 108513, 2020.

[15] L. C. Baiardi and A. K. Naimzada, "An oligopoly model with rational and imitation rules," Mathematics and Computers in Simulation, vol. 156, pp. 254-278, 2019.

[16] L. C. Baiardi, A. K. Naimzada, and A. Panchuk, "Endogenous desired debt in a Minskyan business model," Chaos, Solitons and Fractals, vol. 131, Article ID 109470, 2020.

[17] G. P. Cachon, "The allocation of inventory risk in a supply chain: push, pull, and advance-purchase discount contracts," Management Science, vol. 50, no. 2, pp. 222-238, 2004.

[18] G. Cai, "Channel selection and coordination in dual-channel supply chains," Journal of Retailing, vol. 86, no. 1, pp. 22-36, 2010.

[19] L. Dai, X. Wang, X. Liu, and L. Wei, "Pricing strategies in dual-channel supply chain with a fair caring retailer," Complexity, vol. 2019, Article ID 1484372, 23 pages, 2019.

[20] J. Raju and Z. J. Zhang, "Channel coordination in the presence of a dominant retailer," Marketing Science, vol. 24, no. 2, pp. 254-262, 2005.

[21] Y. Wang and X. Sun, "Dynamic vs. static wholesale pricing strategies in a dual-channel green supply chain," Complexity, vol. 2019, Article ID 8497070, 14 pages, 2019.

[22] R. Yan, "Managing channel coordination in a multi-channel manufacturer-retailer supply chain," Industrial Marketing Management, vol. 40, no. 4, pp. 636-642, 2011.

[23] J. Zhang, G. Liu, Q. Zhang, and Z. Bai, "Coordinating a supply chain for deteriorating items with a revenue sharing and cooperative investment contract," Omega, vol. 56, pp. 37-49, 2015.

[24] S. Zhang and J. Zhang, "Agency selling or reselling: E-tailer information sharing with supplier offline entry," European Journal of Operational Research, vol. 280, no. 1, pp. 134-151, 2020.

[25] Q. Lu, V. Shi, and J. Huang, "Who benefit from agency model: a strategic analysis of pricing models in distribution channels of physical books and e-books," European Journal of Operational Research, vol. 264, no. 3, pp. 1074-1091, 2018.

[26] D. C. Dantas, S. Taboubi, and G. Zaccour, "Which business model for e-book pricing?” Economics Letters, vol. 125, no. 1, pp. 126-129, 2014.
[27] N. Singh and X. Vives, "Price and quantity competition in a differentiated duopoly," The RAND Journal of Economics, vol. 15, no. 4, pp. 546-554, 1984.

[28] C. Chang and Z. Yao, "Comparison between the agency and wholesale model under the e-book duopoly market," Electronic Commerce Research, vol. 18, no. 2, pp. 313-337, 2018.

[29] M. D. Smith and R. Telang, "Piracy or promotion? The impact of broadband internet penetration on DVD sales," Information Economics and Policy, vol. 22, no. 4, pp. 289-298, 2010.

[30] B. Sun, "Online retail sales of China continue to win the first place all over the world in 2015," 2016, http://finance.people. com.cn/n1/2016/0223/c1004-28143131.

[31] A. Arya, B. Mittendorf, and D. E. M. Sappington, "The bright side of supplier encroachment," Marketing Science, vol. 26, no. 5, pp. 651-659, 2007.

[32] Z. Li, S. M. Gilbert, and G. Lai, "Supplier encroachment as an enhancement or a hindrance to nonlinear pricing," Production and Operations Management, vol. 24, no. 1, pp. 89-109, 2015.

[33] R. Wischenbart, "The global ebook report 2015: a report on market trends and developments," Rdiger Wischenbart Content and Consulting, Vienna, Austria, 2015.

[34] S. S. Askar and K. Alnowibet, "Nonlinear oligopolistic game with isoelastic demand function: rationality and local monopolistic approximation," Chaos, Solitons \& Fractals, vol. 84, pp. 15-22, 2016.

[35] A. K. Naimzada and L. Sbragia, "Oligopoly games with nonlinear demand and cost functions: two boundedly rational adjustment processes," Chaos, Solitons \& Fractals, vol. 29, no. 3, pp. 707-722, 2006.

[36] T. Puu, Attractors, Bifurcations and Chaos: Nonlinear Phenomena in Economics, Seconded, Springer, Berlin, Germany, 2003.

[37] R. L. Devaney, An Introduction to Chaotic Dynamical Systems, Benjamin-Cummings, Menlo Park, CA, USA, 2nd edition, 1989.

[38] H. W. Lorenz, Nonlinear Dynamical Economics and Chaotic Motion, Springer-Verlag, Berlin, Germany, 1989.

[39] J. Zhou, W. Zhou, T. Chu, Y.-X. Chang, and M.-J. Huang, "Bifurcation, intermittent chaos and multi-stability in a twostage Cournot game with R\&D spillover and product differentiation," Applied Mathematics and Computation, vol. 341, pp. 358-378, 2019.

[40] A. E. Matouk, A. A. Elsadany, and B. Xin, "Neimark-Sacker bifurcation analysis and complex nonlinear dynamics in a heterogeneous quadropoly game with an isoelastic demand function," Nonlinear Dynamics, vol. 89, no. 4, pp. 2533-2552, 2015.

[41] B. Xin and Z. Wu, "Neimark-Sacker bifurcation analysis and 0-1 chaos test of an interactions model between industrial production and environmental quality in a closed area," Sustainability, vol. 7, no. 8, pp. 10191-10209, 2015.

[42] C. Mira, L. Gardini, A. Barugola, and J. C. Cathala, Chaotic Dynamics in Two-Dimensional Noninvertible Maps, World Scientific, Singapore, 1996.

[43] A. Agliari, G.-I. Bischi, R. Dieci, and L. Gardini, "Global bifurcations of closed invariant curves in two-dimensional maps: a computer assisted study," International Journal of Bifurcation and Chaos, vol. 15, no. 4, pp. 1285-1328, 2005.

[44] J. Andaluz and G. Jarne, "Stability of vertically differentiated Cournot and Bertrand-type models when firms are boundedly rational," Annals of Operations Research, vol. 238, no. 1-2, pp. 1-25, 2016. 
[45] G. I. Bischi and M. Kopel, "Equilibrium selection in a nonlinear duopoly game with adaptive expectations," Journal of Economic Behavior \& Organization, vol. 46, no. 1, pp. 73-100, 2001.

[46] G. I. Bischi, C. Chiarella, and I. Sushko, Global Analysis of Dynamic Models in Economics and Finance: Essays in Honour of Laura Gardini, Springer-Verlag, Berlin, Germany, 2013.

[47] A. Gardini, G. I. Bischi, and L. Gardini, "Some methods for the global analysis of dynamic games represented by iterated noninvertible maps," in Oligopoly Dynamics: Models and Tools, pp. 31-83, Springer, Berlin, Heidelberg, 2002.

[48] G. I. Bischi, L. Gardini, and M. Kopel, "Analysis of global bifurcations in a market share attraction model," Journal of Economic Dynamics and Control, vol. 24, no. 5-7, pp. 855879, 2000. 